\title{
EL PROBLEMA DE LA AUTORIDAD: DE NUEVO SOBRE LA CONCEPCIÓN DE LA AUTORIDAD COMO SERVICIO
}

\author{
Joseph Raz * \\ Universidad de Oxford
}

RESUMEN. El objeto de este artículo es volver de nuevo sobre la concepción de la autoridad como servicio, examinando algunas de las críticas que se le han dirigido. En la primera sección se exponen los presupuestos metodológicos fundamentales de la concepción. En la segunda sección se esbozan los perfiles generales de la concepción de la autoridad como servicio, así como la manera en la que ésta aborda el problema de la autoridad. En la sección tercera se exponen brevemente una serie de dificultades adicionales a las que se enfrenta la concepción, refinando la teoría y exhibiendo alguna de sus ventajas. En la sección cuarta se examina a grandes rasgos el argumento de que la autoridad, o al menos la autoridad política, presupone un vínculo especial, ausente en la concepción de la autoridad como servicio, entre el gobierno y los gobernados. En la sección quinta se considera la posibilidad de que tal vínculo sea forjado por el consentimiento, mientras que en la sección sexta se examina la posibilidad de que el vínculo se constituya en virtud de la identificación con o la pertenencia a la comunidad política (o a algún otro grupo).

Palabras clave: Legitimación de la autoridad, la concepción de la autoridad como servicio.

ABSTRACT. The purpose of Raz in this article is to revisit the service conception of authority. The author focuses his attention on some of the objections that were addressed to this conception. In the first section of his work, the fundamental methodological premises of the conception are explained. In the second section, the main features of the service conception are introduced to the reader, as well as how this conception approaches the problem of authority. In the third section, several additional difficulties confronting the conception are explored; all this considerations help the author to perfect his theory, showing then some of its advantages. In the fourth section, it is briefly considered the argument on the special link presumed between government and citizens specifically in the case of political authorities and how this argument is missing in the service conception. In the fifth section, it is taken into consideration the possibility for that link to be forged by consent, whereas in the sixth section, it is considered whether that link should be constituted by identification with or membership of the political community (or any other group).

Keywords: Legitimation of Authority, the Service Conception of Authority.

* Profesor de Filosofía del Derecho de la Universidad de Oxford y profesor en la Facultad de Derecho de la Universidad de Columbia. En la redacción de este artículo me he beneficiado de diferentes comentarios sobre mis ideas, orales o publicados, de más personas de las que recuerdo. Entre aquellos con los que tengo una deuda de gratitud están Jules Coleman, Ronald Dworkin, Lesley Green, Herbert HarT, Scott HeRShovitz, Heidi Hurd, Michael Moore, Stephen Perry, Donald Regan, Philip Soper y Jeremy Waldron; la mayoría de ellos encontrará insuficiente mi respuesta a sus comentarios. 


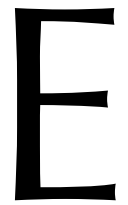

1 problema que tengo en mente es el problema de la posible justificación de someter la propia voluntad a la de otro y del estatus normativo de las exigencias para hacerlo. La teoría de la autoridad que ofrecí hace muchos años ${ }^{1}$ bajo el título de concepción de la autoridad como servicio encaró esta cuestión y asumió que todos los otros problemas relacionados con la autoridad quedan subsumidos en la concepción. Muchos encontraron la teoría implausible. Es poco densa, ya que se basa en muy pocas ideas. Bien puede parecer que es demasiado poco densa y que se aparta demasiado de muchas de las ideas que han ganado aceptación general en la historia de la reflexión sobre la autoridad.

La crítica puede ser radical y rechazar completamente la concepción de la autoridad como servicio. O puede ser más moderada y aceptar la concepción de la autoridad como servicio o algunos de sus rasgos centrales, particularmente la tesis de la justificación normal, en tanto que establece condiciones necesarias para la legitimidad de la autoridad, pero negar que constituyan condiciones suficientes. Generalmente, los críticos moderados sostienen que la autoridad legítima, en todo caso la autoridad política legítima, presupone una conexión especial entre gobernantes y gobernados, vínculo especial que es pasado por alto por la concepción de la autoridad como servicio. Mi propósito es volver al problema de la autoridad y examinar las posiciones moderamente críticas o algunas de ellas. Empezaré explicando en la primera sección algunos presupuestos metodológicos de fondo. En la parte 2 se reiterará brevemente la concepción de la autoridad como servicio y la manera en que se trata el problema de la autoridad. En la parte 3 se desarrolla la concepción de la autoridad como servicio y se elaboran algunas de sus implicaciones, abordando una serie de cuestiones sólo vagamente conectadas y dudas a las que está abierta. En la parte 4 se examina en términos generales el argumento de que la autoridad, en todo caso la autoridad política, presupone un vínculo especial, ausente en la concepción de la autoridad como servicio, entre el gobierno y los gobernados. En la parte 5 se considera la posibilidad de que tal vínculo sea forjado por el consentimiento, mientras que en la parte 6 se comenta la posibilidad de que el vínculo sea constituido por identificación con la comunidad política o pertenencia a la misma (o a algún otro grupo).

\section{ALGUNAS OBSERVACIONES METODOLÓGICAS}

Para empezar, unas pocas observaciones sobre el enfoque general.

Primero, autoridad, obligación política y obligación de obedecer al Derecho: algunos autores piensan que la llamada obligación política es la obligación de obedecer al Derecho y que uno tiene una obligación de obedecer al Derecho si y sólo si el Derecho o las instituciones jurídicas tienen autoridad legítima. Eso es un error, y lo es aun cuando restrinjamos nuestra atención tan sólo a las autoridades jurídicas. La obligación política es la más amplia de las tres nociones, comprendiendo a las obligaciones que los

\footnotetext{
${ }^{1}$ Algunas de las ideas básicas aparecen en RAZ, J., 1979: The authority of law; los principales elementos de la concepción de la autoridad como servicio están establecidos en RAz, J., 1986: The morality of freedom.
} 
miembros de una comunidad política tienen hacia ella, o hacia sus instituciones y orden político, en virtud de su pertenencia a dicha comunidad. Ella incluye mucho más y mucho menos que una obligación de obedecer al Derecho. Más, porque incluye algunos deberes de buen ciudadano en formas que tienen poco que ver con el Derecho. Se trata de deberes como el de reaccionar contra la injusticia perpetrada por o en nombre de la comunidad, el de contribuir a su funcionamiento adecuado (p.e., votando y siendo activo de diversas maneras) y otros. Requiere menos que obedecer al Derecho, en tanto que buena parte del Derecho no tiene nada que ver con la comunidad política. Si tomo la manzana de mi vecino y me la como puedo estar violando al Derecho, pero es improbable que esté haciendo algún daño a la comunidad. No es necesario que las obligaciones de obedecer al Derecho dependan de la legitimidad de sus autoridades. Podrían existir varias razones, incluso razones morales, para obedecer al Derecho de un país cuyas autoridades jurídicas no son legítimas. A menudo se piensa que proporcionan tales razones consideraciones relativas a la estabilidad y la protección de intereses adquiridos ${ }^{2}$. Finalmente, vale la pena mencionar que tenemos deberes políticos que no dependen ni de la pertenencia a una comunidad política ni de estar sometido a sus leyes. El deber de RAWLS de sostener y apoyar instituciones justas es de este tipo, y se aplica a todos nosotros, con respecto a cualquier institución justa, en cualquier lugar en que se encuentren ${ }^{3}$. Este artículo se ocupa exclusivamente de la naturaleza de la autoridad.

Segundo, poder y derecho: en nuestro uso común del concepto de autoridad, poder y derecho a mandar se entremezclan. Cualquier intento por separarlos está destinado a tener algo de artificial. Sin embargo, debemos hacerlo, porque parecen estar interrelacionados de alguna manera sistemática que invita a describir sus contribuciones distintivas al concepto de autoridad. Mi sugerencia fue que incluso la noción de mera autoridad de facto (aquella que ejercita poder sobre sus súbditos pero que carece del derecho para hacerlo) implica la de legitimidad. Lo que hace a las meras autoridades de facto diferentes de las personas o grupos que ejercen el poder desnudo (p.e. aterrorizando a una población, o manipulándola) es que las autoridades de facto pretenden, y aquellos que tienen el poder desnudo no, tener un derecho a gobernar a aquellos sometidos a su poder. Ellas pretenden legitimidad. Ellas actúan, como yo digo, so pretexto de legitimidad ${ }^{4}$.

Por otro lado, sugerí que las autoridades legítimas no son siempre autoridades de facto. Cabe sostener que el gobierno legítimo de Polonia en 1940 era el gobierno en el exilio en Londres, aunque no gozara de poder sobre la población de Polonia 5 . La

\footnotetext{
${ }^{2}$ Varios sistemas jurídicos reconocen tales razones al tener doctrinas que otorgan efecto jurídico a las autoridades de facto.

${ }_{3}$ Véase Rawls, J., ed. rev. 1999: A theory of justice, pp. 293-294.

${ }^{4}$ Incluso aquellos que no pretenden un derecho a gobernar pretenden — dejando a un lado casos excepcionales - que ellos tienen permitido actuar como lo hacen, que sus acciones son defendibles. Pero ellos no pretenden que aquellos sobre quienes ejercen el poder les deben obediencia, es decir, que tengan un deber de obedecerlos. Están satisfechos con ser capaces de hacerlos obedecer, mediante amenazas crébles o de alguna otra manera.

5 Posiblemente el gobierno en el exilio gozó de algunos poderes de facto (había un ejército polaco --también en el exilio- que lo reconoció, etc.), pero su legitimidad no dependía de la posesión de ese poder. Su legitimidad dependía, sin embargo, de un hecho no normativo, de ser reconocido como legítimo por la mayoría de la población polaca y por algunos otros países. En otras circunstancias la legitimidad
} 
metodología resultante también se aplica a la clarificación de otros conceptos: hay una clase de conceptos normativos que tienen un uso secundario, en el cual indican una pretensión por parte de sus usuarios, o de algunos de ellos, de que ellos se aplican en su sentido primario, normativo; pretensión que puede ser errónea. El concepto más importante de este tipo es el de razón (normativa) ${ }^{6}$. Una razón para una acción es una consideración que presenta su elección inteligible y que cuenta a su favor. Pero cuando digo que «mi razón para salir fue que temía perder el último autobús», indico la razón que creí que tenía en ese momento para salir (el hecho de que iba a perder el último autobús si no salía), sin estar comprometido con el hecho de que haya existido efectivamente tal razón.

Si eso es correcto, entonces el concepto de autoridad legítima tiene prioridad explicativa sobre el de mera autoridad de facto. El segundo presupone al primero, pero no al revés. De aquí en adelante, "autoridad" se refiere a autoridad legítima.

Tercero, posesión y aplicación del concepto: no es literalmente verdadero que "autoridad" sea un concepto que sólo se aplica a personas que piensan que se aplica a ellas. Puede haber autoridades que no pretendan tener autoridad. Sin embargo, como se acaba de explicar, las autoridades de facto sí pretenden tener autoridad legítima y, como se verá más adelante, las autoridades políticas generalmente la pretenden. La pregunta que surge es si es una condición de adecuación de una explicación del concepto de autoridad que aquellos que tienen autoridad por lo menos implícitamente acepten la explicación como correcta. (Por otro lado, ¿se puede aceptar una explicación del concepto como de validez limitada, en el sentido de sólo aplicarse a las personas — quizás en ejercicio de la autoridad o quizás sometidas a la autoridad- que, por lo menos implícitamente, la toman como una explicación verdadera?).

No. Si las personas disputan una teoría de la autoridad que, por otra parte, está bien fundada, cometen un error. La concepción de la autoridad como servicio es una teoría de la autoridad que incluye una explicación de lo que es tener autoridad, de lo que es estar sometido a la autoridad, cuándo uno tiene autoridad o está sometido a ella, y preguntas similares. La teoría no es acerca de lo que la gente piensa que es tener autoridad o estar sometido a ella, sino acerca de lo que es tenerla o estar sometido a ella. Es compatible con afirmaciones que digan que las personas tienen diferentes creencias acerca de estas cuestiones, aunque se siga de la teoría que las suyas son creencias equivocadas. ¿Se sigue que son culpables de una confusión conceptual? Peor aún, ¿'se sigue que no conocen su propio idioma? Claro que no. Si tienen creencias falsas sobre la autoridad (no meramente sobre los poderes de las personas que realmente tienen autoridad), entonces tienen el concepto de autoridad, tienen alguna comprensión de lo que involucra. Pero su comprensión es parcial y en parte incorrecta.

puede depender de las posibilidades del gobierno de lograr un control eficaz. Esto permite mantener la distinción entre autoridad sin el poder de ejercerla eficazmente y alguien que tiene derecho a tener autoridad (por ejemplo, fue debidamente elegido) pero no la tiene (p.e., porque no fue admitido para el cargo para el que fue elegido). Contrasta con este caso un padre que tiene autoridad sobre su hijo aun cuando carece de poder sobre él.

${ }^{6}$ Las califico como "normativas" para distinguirlas de las razones explicativas, que son simplemente hechos o acontecimientos que explican cómo o por qué son las cosas. 
Nuestra comprensión de los conceptos normalmente lo es. Deja mucho espacio para errores y desacuerdos ${ }^{7}$.

Cuarto, esperanzas de neutralidad: algunos autores entienden que su tarea es proporcionar una explicación normativamente neutral de los conceptos normativos, tal como el de "autoridad", que sea consistente con cualquier opinión normativa posible ${ }^{8}$. No está claro si hay un sentido en el cual ésta pueda ser una exigencia razonable. Si sólo es satisfecha explicando conceptos normativos exclusivamente en términos no normativos (o no evaluativos), equivale a un requisito de reducción semántica de todos los conceptos normativos a los que se aplica, y en esa forma no hay ninguna razón para aceptarla como un requisito metodológico general. Por otro lado, se puede entender que requiere que, aunque las explicaciones de los conceptos normativos pueden basarse en otros conceptos normativos o evaluativos, éstos deben ser tales que cualquiera, cualesquiera que sean sus creencias normativas o valorativas, se encuentra comprometido a aceptar que posiblemente ${ }^{9}$ tengan casos que lo ejemplifiquen que sean verdaderos (o válidos). Así entendido, el requisito tiende a una reducción semántica de términos normativos o evaluativos densos a finos. No está claro, sin embargo, que muchos términos normativos cumplan este requisito. Es dudoso que muchos conceptos densos puedan reducirse a finos.

Quizás el requisito de neutralidad tenga que ser entendido como una cuestión de grado: cuanto más se aproxime una explicación a satisfacerlo, mejor explicación es, siendo las otras cosas iguales. Después de todo, las explicaciones que cumplen este requisito, o más bien los conceptos que ellas explican con éxito, pueden ser aceptados y usados por las personas, cualesquiera sean sus creencias normativas.

Algunas personas piensan que la explicación de la autoridad debe ser normativamente neutral en otro sentido. Piensan que la explicación de la autoridad debe ser tal que sea posible para la proposición "X tiene autoridad sobre $Y$ " tener casos que la ejemplifiquen que sean verdaderos; que sea posible que alguien sea autoridad legítima sobre otros. Llamemos al primer tipo de neutralidad normativa "neutralidad explicativa", y al segundo tipo "neutralidad existencial".

La neutralidad existencial tiene la ventaja de no chocar con la opinión de que puede haber autoridades legítimas, una opinión que es ampliamente sostenida, y que lo ha sido a lo largo de la historia, dondequiera que las personas tuvieron una opinión sobre el tema. La gente puede cometer errores, incluso errores normativos; sin embargo, una explicación de un concepto que es ampliamente usado, y que más o menos universalmente se cree que tiene aplicaciones, pero que, en combinación con creencias normativas verdaderas, implica que no tiene ninguna, tiene la difícil tarea de dar cuenta de cómo es que la gente está tan equivocada.

Es posible exagerar la dificultad de la tarea. Primero, es posible explicar cómo es que las personas están generalmente equivocadas sobre la posibilidad de la autoridad

\footnotetext{
Véase RAZ, J., 2001: «Two Views of the Nature of the Theory of Law: A Partial Comparison», Hart's postscript 1 (Jules Coleman ed.).

${ }_{8}$ Por ejemplo, si una explicación correcta del deshonor implica que a) aquellos que actuaron deshonrosamente merecen ser matados, y $b$ ) que cualquiera que traiciona la confianza actuó deshonrosamente, entonces esa explicación se contradice con mis opiniones normativas.

${ }^{9}$ En el sentido no epistémico de "posiblemente".
} 
legítima sin necesidad de atribuirles una equivocación gruesa sobre el concepto. Su error, si es que están equivocadas, bien pudiera estar en algunas de sus creencias normativas, más que en su comprensión conceptual ${ }^{10}$. Segundo, los conceptos tienen una historia, y las condiciones de su persistencia o identidad a través del tiempo son, en el mejor de los casos, muy vagas. Por lo tanto, puede ser que la imposibilidad de la autoridad legítima sea la imposibilidad de existir ejemplos de nuestro concepto actual de autoridad. Posiblemente, bajo algunos ascendientes de nuestro concepto la autoridad legítima fue posible. Lo contrario también es posible, y aún más probable. Una fuente de presión para el cambio del concepto puede haber sido una creciente conciencia de que el concepto entonces prevaleciente no tenía ningún caso que lo ejemplificase (p.e., si alguna vez el concepto de autoridad fue tal que tenía que derivar de la autoridad divina, entonces, el reconocimiento de la imposibilidad de la autoridad divina puede haber fomentado el cambio en el concepto, un cambio que le hizo posible tener casos que lo ejemplificasen, al menos a los ojos de la gente en ese momento).

La teoría que ofrezco tiene casos que ejemplifican el concepto. Pero el obstáculo de ir en contra de la opinión popular puede ser mayor o menor. Por ejemplo, mi teoría tiene como consecuencia que es probable que las autoridades políticas tengan una autoridad más limitada que la que muchas de ellas, quizá todas, pretenden tener, y que la gente generalmente creen que tienen. Ello aún exige explicar por qué las personas están tan equivocadas ${ }^{11}$, aunque, siendo el error atribuido de menor largo alcance, la carga de la explicación también es mucho menor.

Mis anteriores comentarios explicaron qué ventajas encuentro tanto en la neutralidad explicativa como en la existencial. Son insuficientes, sin embargo, para hacer a cualquiera de ellas un principio metodológico. Sospecho que la exigencia de neutralidad explicativa es imposible de satisfacer (es decir, las explicaciones que la satisfacen, si es que existen, son defectuosas en otro sentido). No hay demasiada plausibilidad en ella. No esperamos que todos los conceptos científicos, por ejemplo, sean explicativamente neutros en el sentido de que sus casos de aplicación sean consistentes con todas las teorías científicas posibles. Algunos conceptos científicos pueden trascender a su teoría o pueden trascenderla en mayor o menor medida. Pero muchos no pueden hacerlo. Mutatis mutandis, lo mismo ocurre, sospecho, con los conceptos normativos. Las mismas consideraciones podrían excluir el requisito de la neutralidad existencial. Dejando a un lado los casos especiales, no es un requisito que normalmente impongamos en la explicación de otros conceptos, y no parece haber motivos para imponerlo a los conceptos normativos, en general, o al de autoridad, en particular.

La esperanza de neutralidad se puede expresar en el requisito de que la teoría de la autoridad debe explicar lo que se sigue cuando alguien tiene autoridad, pero no

${ }^{10}$ Abundando en precauciones, permítaseme ampliar aquí: no hay ninguna implicación en los puntos arriba señalados de que una explicación de un concepto para ser correcta tenga que ser una generalmente disponible para aquellos que tienen el concepto. Hay muchos aspectos de un concepto de los que sus usuarios pueden no ser conscientes, y muchos los errores que pueden cometer acerca del mismo. La afirmación meramente fue que se necesitaría una buena explicación acerca de cómo una creencia equivocada sobre la posibilidad de casos que ejemplifiquen el concepto, en nuestro caso una creencia en la posibilidad de autoridades legítimas, pasó a estar tan extendida.

${ }^{11}$ Éste fue un punto que me señaló en privado H. L. A. HART. 
incluirá nada acerca de las condiciones bajo las cuales se puede adquirir o sostener autoridad. Para que este requisito tenga sentido, tiene que ser el caso no sólo de que quien proponga la teoría no escriba sobre las condiciones bajo las cuales se sostiene la autoridad, sino de que tampoco se siga nada de la teoría con respecto a las condiciones que hacen a alguien ser una autoridad. Éste parece ser un requisito imposible de satisfacer: ¿cómo podría ser que la manera de justificar una pretensión de que se tiene autoridad no se ve afectada por, en realidad no es guiada por, lo que tiene que ser justificado, a saber, las consecuencias de tener autoridad?

Hay aún así una diferencia entre las dos partes de la teoría de la autoridad. Podemos razonablemente esperar que una teoría de la autoridad especifique, aunque sea de manera abstracta, todas o al menos las principales consecuencias de tener autoridad. Sin embargo, más allá de decir que las condiciones bajo las cuales uno sostiene autoridad son aquellas que justifican atribuirle autoridad —a saber, atribuirle a sus acciones las consecuencias que se siguen de tener autoridad-, no está claro que uno pueda razonablemente esperar una especificación completa de esas condiciones. Si uno ofrece algunas condiciones suficientes para tener autoridad, surge la pregunta: ¿se puede sostener que ninguna otra condición establece a alguien como autoridad? Demostrar un negativo existencial es notoriamente difícil, y aunque intenté hacer exhaustiva a la teoría que después expondré, no tengo un argumento para mostrar que lo es.

Quinto, posesión de un concepto y límites de su aplicación: la observación sobre la historicidad del concepto de autoridad requiere de un par de breves clarificaciones. Implica dos posibilidades: primero, que hubo un tiempo en el cual el concepto no existía en absoluto y, segundo, que nuestro concepto es un descendiente de conceptos anteriores. Es plausible pensar que los dos son tomados en cuenta, lo que explica cómo es usado el término: a veces para referirse a la serie entera de conceptos que son los ascendientes de nuestro concepto, a veces exclusivamente a nuestro concepto.

¿No se sigue que hay un concepto más amplio, que se usa siempre que usamos el término de la primer manera, o sea, para referirnos a lo que llamé la serie entera de conceptos ascendientes? ¿Y no es éste el concepto verdadero de autoridad? Sí y no. Sí, porque existe tal concepto general. No, porque es engañoso identificar el concepto general con el concepto de autoridad simpliciter. La razón principal es que la manera, y pienso que la única manera, en que la noción amplia puede ser identificada es como yo la identifiqué: históricamente, como el concepto que se aplica a todos los casos de lo que llamé "nuestro" concepto de autoridad y a los de sus ascendientes (más que por sus rasgos ahistóricos). "Nuestro" concepto es el concepto de autoridad, aunque sólo sea porque él es nuestra vía de acceso a todos sus ascendientes, que se identifican por sus relaciones con él.

También es cierto que necesitamos el concepto más amplio, o más bien que regularmente nos basamos en él. Por ejemplo, y crucialmente, no puede haber ninguna autoridad de facto entre personas que no tengan el concepto de autoridad, porque tener autoridad de facto es, entre otras cosas, pretender autoridad legítima. Se sigue que cuando hablamos de autoridades de facto existentes en la Edad Media, o en el Japón del siglo XV, o en la Persia antigua, nos basamos en algo como el concepto amplio: en ese tiempo había personas u organismos con poder sobre poblaciones que 
pretendieron autoridad sobre ellas, utilizando aquí el ascendiente apropiado de nuestro concepto, o el concepto amplio que incluye a todos los ascendientes.

Un concepto es un concepto ascendiente si el concepto que le sucede surgió como una modificación del concepto ascendiente, y conservó suficiente similitud a él, en sus rasgos o en su función. La relación no es típicamente tan sólo de similitud. Contiene un componente causal contingente. De manera típica, si ello no se diera, como cuando nos encontramos en una cultura diferente con un concepto no causalmente relacionado pero similar, identificaríamos al concepto simplemente así: «Ellos —diríamos-, también tenían un concepto como (o similar a) nuestro concepto de...». Por otro lado, la similitud es parte de la relación ancestral, ya que de otra manera no tendríamos ningún criterio para distinguir entre un concepto que es modificado por uno sucesor y uno que es rechazado en favor de otro alternativo.

Huelga decir que, dado que el concepto amplio es identificado por sus relaciones con nuestro concepto y sus ascendientes, y dado que "nuestro" concepto puede cambiar con el tiempo y adquirir más ascendientes, el concepto global que ahora tenemos es diferente del que teníamos o tendremos, cuando "nuestro" concepto fue diferente o será diferente.

Sexto, explicación y defensa: sigo refiriéndome a "nuestro" concepto de autoridad. Pero ¿existe tal cosa? ¿No hay acaso varios conceptos, todos ellos descendientes de los mismos ascendientes? Es bastante posible que así sea. Cada persona al usar el concepto de autoridad usa su concepto y debe permitir la posibilidad de que haya varios. Ello no lleva a una explosión de conceptos. La razón es simple: en el uso de conceptos concedemos que somos ignorantes acerca de muchos aspectos relativos a ellos, que podemos usarlos incorrectamente, y que su carácter viene determinado por las reglas que gobiernan su uso en la comunidad, reglas cuya comprensión completa puede escapar a alguno o, de hecho, a todos nosotros. Al conceder la posibilidad de, por lo menos, ignorancia parcial respecto de la naturaleza de nuestros conceptos, reconocemos que los conceptos son entidades sociales y que deben sus rasgos a una comunidad de hablantes de maneras tales que pueden escapárseles a cualquiera de ellos o, de hecho, a todos ellos. Esto significa que nuestros conceptos no son muy idiosincrásicos, que existen conceptos comunes, aun cuando podemos no conocer todos sus rasgos.

Ni que decir tiene, si hay una serie de conceptos de autoridad prevalentes en una misma sociedad, es probable que compitan entre sí. Los límites entre ellos son fluidos, y quienes usan cada uno afirman su mérito propio, y (si son conscientes, aunque sólo sea vagamente, de la existencia de los otros) encuentran una razón para preferirlo a los otros. Esto significa que cada explicación de un concepto también puede ser usada en la batalla de los conceptos, cuando exista tal batalla; es decir, se puede usar para defender los méritos de un concepto frente a sus competidores.

La indeterminación de los conceptos es otro factor que obliga a que todas las explicaciones entren, si tienen éxito, en la tarea de la defensa. Las explicaciones pueden procurar reproducir las indeterminaciones de los conceptos que explican, pero es casi imposible reproducirlas perfectamente, y el éxito de la explicación ejercerá inevitablemente alguna influencia en el cambio del concepto para hacerlo conformarse con su explicación. 


\section{LA CONCEPCIÓN DE LA AUTORIDAD COMO SERVICIO EN POCAS PALABRAS}

La concepción de la autoridad como servicio está guiada por dos problemas, uno teórico y otro moral. Partiendo de la idea común, a la que en términos generales y con las reservas y aclaraciones apropiadas me sumo, de que la autoridad es un derecho a gobernar, la pregunta teórica es cómo entender la existencia de una directiva autoritativa (que es como llamaré al producto del ejercicio del derecho a gobernar). Si fue emitida por quien tiene un derecho a gobernar, entonces sus destinatarios están obligados a obedecer. La directiva es vinculante para ellos, y ellos tienen el deber de obedecerla ${ }^{12}$. Pero ¿cómo puede ser que el solo decir de una persona constituya una razón, un deber, para otra? ¿Es tan fácil crear deberes de la nada?

La pregunta moral es ¿cómo puede ser que alguien tenga un deber de someter su propia voluntad y juicio a los de otra persona? Por supuesto, somos afectados por otros y por las acciones de otros de innumerables maneras. A menudo actuamos para inducir a otros a ayudarnos o a no ponernos trabas, a colaborar con nosotros en empresas comunes, a evitar herirnos o a tornar sus acciones en nuestro beneficio. Pero el caso de la autoridad es especial. Las directivas emitidas por la autoridad aspiran a constituir razones para sus súbditos y son vinculantes para ellos porque fueron pensadas para que lo sean. Si reconocemos un deber de obedecerlas reconocemos que tienen un derecho a darnos órdenes, no sólo a afectar las circunstancias que conforman nuestras oportunidades y obstáculos en nuestro camino. Las autoridades nos dicen qué intentar hacer, con el objetivo de lograr cualquier meta que ellas persigan ordenando nuestra voluntad. ¿Puede algún ser humano tener tal poder normativo sobre otro? ¿Puede en algún caso ser correcto reconocer a otro tal poder sobre uno mismo?

El problema teórico es similar al que presentan las promesas (y todas las empresas voluntarias). Al prometer imponemos sobre nosotros mismos obligaciones que antes no teníamos, y lo hacemos simplemente comunicando una intención de hacerlo. Al ejercer autoridad imponemos a otros deberes que antes no tenían, y lo hacemos simplemente expresando una intención de hacerlo ${ }^{13}$. ¿Cómo la acción de comunicar intenciones de crear razones u obligaciones (para nosotros mismos o para otros) puede crearlas tan sólo porque comunican esas intenciones?

Un comienzo de respuesta es advertir que básicamente no hay nada especial en tales casos. Varias de nuestras acciones contraen obligaciones. A menudo se asume que concebir y dar a luz a un niño es un caso tal. Otro es infringir los derechos de

${ }^{12}$ Las autoridades hacen mucho más que imponer deberes. Pero cualquier cosa que hagan —conferir poderes o derechos, conceder permisos o inmunidades, cambiar estatus, crear y extinguir personas jurídicas (sociedades y similares), regular las relaciones entre los órganos de personas jurídicas, y mucho más- lo hacen imponiendo deberes, reales o condicionales. Por consiguiente, como hacen en general los autores sobre la autoridad, yo continuaré discutiendo el problema de la autoridad en relación con su derecho a imponer deberes.

${ }_{13}$ En ambos casos, algunas veces la persona colocada bajo una obligación ya tenía una obligación de realizar el mismo acto. «Una obligación que antes no tenía» no significa una obligación de hacer algo que hasta entonces no tenía ninguna obligación de hacer. La obligación es nueva aun cuando ya existiese otra obligación para realizar el mismo acto. 
otras personas (genera una obligación de reparar, etc.). Las afirmaciones de que tenemos una obligación debido a lo que hicimos o debido a cómo actuamos son verdaderas, en su caso, en virtud de razones generales a favor de que quienes actuaron de determinadas maneras tengan determinadas razones u obligaciones. Se asume que existen razones generales para cualquiera que tenga un niño de cuidarlo, una razón general para cualquiera que viola el derecho de otros de compensarlos, y así sucesivamente.

Las promesas y las autoridades no son ninguna excepción. No siempre que alguien actúa con la intención de contraer una obligación hacia alguien realiza una promesa vinculante. Una promesa sólo es vinculante si la acción prometida es de una clase respecto de la cual hay razones suficientes para mantener al promitente vinculado por su promesa. Esto significa que, para ser vinculantes, las promesas deben reunir muchas condiciones: el promitente debe ser capaz de conocer el significado de su acción, debe ser capaz de tener una comprensión razonable de sus consecuencias probables y, lo más importante, $a$ ) el acto prometido debe pertenecer a una clase de acciones tal que el ser capaz de hacer tales promesas refuerza el control de las personas sobre sus vidas, y b) el acto no debe ser gravemente inmoral, etc. Ni una promesa de ser esclavo ni una promesa de hacer a alguien esclavo es vinculante, y así sucesivamente.

La pregunta teórica sobre la naturaleza de la autoridad se responde de manera similar. Una persona puede tener autoridad sobre otra sólo si hay razones suficientes para que esta última esté sometida a deberes cuando así lo diga la primera. Ello, claro, aunque sea probablemente correcto, no nos dice cuándo una persona tiene autoridad sobre otra. Ni siquiera establece que alguien pueda en algún caso tener autoridad. Pero establece lo que se tiene que dar si algunas personas tienen autoridad sobre otras. Eso es todo lo que se puede pedir a una teoría general de la autoridad, a saber, que establezca lo que considera que ha de darse para que exista una autoridad legítima, más que mostrar quién tiene autoridad sobre quién y con respecto a qué. Esta última tarea es una cuestión de evaluar casos individuales. Pero, por supuesto, una teoría general de la autoridad puede, aun no estableciendo quién realmente tiene autoridad, decir mucho más acerca de las condiciones bajo las cuales las personas están sometidas a la autoridad. En particular, esperaríamos que encarase el problema moral acerca de la autoridad, a saber, ¿cómo puede ser consistente con ser persona el estar sujeto a la voluntad de otro de la manera en que uno lo está cuando se encuentra sometido a la autoridad de otro?

La sugerencia de la concepción de la autoridad como servicio es que la pregunta moral se responde cuando se cumplen dos condiciones y con respecto a los problemas en relación con los cuales esas condiciones se cumplen: primera, que el sometido se conformaría mejor con razones que de todos modos le son aplicables (es decir, con razones distintas de las directivas de la autoridad) si intenta ${ }^{14}$ ser guiado por las directivas de la autoridad que si no lo hace (me referiré a ella como la tesis o condición de la justificación normal). Segunda, que las cuestiones respecto de las cuales se reúne la primera condición son tales que en relación a ellas es mejor conformarse con la razón

${ }^{14}$ Quizás debería decir "tratar" más que "intentar" para cubrir los casos donde, aunque uno intenta ser guiado por la autoridad, fracasará por debilidad de la voluntad y, por tanto, haría mejor en ignorar a la autoridad e intentar conformarse con las razones de fondo. Probablemente existan interminables refinamientos de este tipo, que no intentaré proporcionar y que probablemente sean imposibles de enumerar. 
que decidir por uno mismo, sin la ayuda de la autoridad (me referiré a ella como la condición de independencia).

Los ejemplos simples de regulaciones relativas a actividades o materiales peligrosos ilustran el punto. Puedo evitar mejor ponerme en peligro a mí y a otros conformándome con el Derecho sobre distribución y uso de productos farmacéuticos. Puedo confiar en los expertos cuyo consejo muestra que conocen lo que es peligroso en estas cuestiones mejor de lo que yo puedo juzgar por mí mismo, hecho que es reforzado por mi confianza en la conformidad de otras personas al Derecho, lo cual me permite actuar con una seguridad que de otro modo no tendría. Por supuesto que nada de ello es necesariamente así. El Derecho puede reflejar los intereses de las compañías farmacéuticas y no los de los consumidores. Si eso es así podría carecer de autoridad sobre mí porque no reúne la condición de la justificación normal ${ }^{15}$. Pero si cumple la condición de la justificación normal es probable que también cumpla la condición de independencia. Las decisiones sobre la seguridad de los productos farmacéuticos no son la clase de decisiones personales respecto de las cuales debo decidir por mí mismo en lugar de seguir a la autoridad. Ellas no me exigen usar ninguna droga, etc., y en este sentido son diferentes de las decisiones acerca de someterse a una medicación o tratamiento, donde bien podemos sentir que debo decidir por mí mismo, en lugar de ser mandado por la autoridad.

Dije que las dos condiciones resuelven la pregunta moral sobre la autoridad. Pero ¿en qué sentido lo hacen? Pueden anticiparse varias objeciones. La condición de independencia, puede objetarse, meramente reitera el problema y no ayuda a solucionarlo. Toda la cuestión en relación con el problema moral es que actuar por uno mismo es lo más importante. ¿Qué ganamos con decir que la autoridad es legítima sólo cuando actuar por uno mismo es menos importante que conformarse con la razón?

Otra objeción a la condición de independencia consiste en que la misma sugiere que se puede comparar la importancia de conformarse con la razón con la importancia de decidir por uno mismo independientemente de la autoridad. Pero esto, dice la objeción, no se puede hacer: las dos son preocupaciones muy diferentes, inconmensurables. ¿No hay nunca una respuesta a la pregunta de cuál de las dos es más importante? Dudo que esta objeción sea válida. Parece estar basada en la premisa de que las preocupaciones que subyacen a las razones con las cuales debemos conformarnos y las que subyacen a la razón para actuar independientemente de la autoridad no tienen nada que ver entre sí. Pero eso no es así.

Algunas de las razones para confiar en el propio juicio derivan de la necesidad de cultivar la habilidad de confiar en uno mismo, simplemente porque a menudo uno no tiene nadie más en quien confiar. El caso más claro es la manera en que los padres deben otorgar a sus hijos libertad para decidir por sí mismos en un rango de cuestiones que gradualmente se vaya ensanchando, a pesar de saber que ellos, los padres, harían una mejor elección para sus hijos en el caso de decidir ellos sobre esas cuestiones. Ésa es la manera en que los niños aprenden a decidir por sí mismos y a con-

15 Tan sólo a efectos del ejemplo he ignorado el complicado hecho de que la autoridad del Derecho es más amplia que la relativa a la posesión y uso de productos farmacéuticos. Esto plantea la cuestión de la unidad de evaluación en la determinación de la legitimidad de las autoridades, que se discutirá más adelante. 
vertirse en seres autosuficientes. Hay otras razones para decidir por uno mismo. Ciertas cuestiones, de acuerdo a las formas sociales de varias culturas, tienen que ser decididas por uno mismo. Por ejemplo, mientras que en algunas formas de matrimonio los padres escogen a los esposos, en otras ni los padres ni ninguna otra persona se espera que tenga algo que decir sobre el asunto. En tales casos no se puede entablar la relación, o embarcarse en el bien o en la actividad, a menos que uno lo haga por sí mismo, no a través de un agente ni siguiendo a un superior.

El primer argumento de la autoconfianza (padres e hijos) es instrumental cuando el fin es asegurar lo que la conformidad con la razón, a la larga, asegurará; el segundo argumento (matrimonio) depende del hecho de que haya razones que sólo pueden ser satisfechas por una acción independiente ${ }^{16}$. Ambos rastrean las preocupaciones que hay detrás de la independencia de vuelta a las preocupaciones por la satisfacción de razones. La idea de que las dos preocupaciones nunca se cruzan y son inconmensurables es injustificada. La cuestión acerca del rol de lo que llamé independencia también involucra otras consideraciones, quizás más fundamentales. No somos totalmente nosotros mismos si demasiadas de nuestras decisiones no son tomadas por nosotros, sino por agentes, autómatas o superiores. Por el otro lado, a veces es nuestro deber, nuestro deber moral si se quiere, aceptar a la autoridad. A veces — por ejemplo, en la escena de un accidente- la coordinación, que en esas circunstancias requiere reconocer a alguien que esté a cargo del rescate, es esencial para salvar vidas. Debemos ceder ante la autoridad cuando haya alguien capaz de jugar ese rol. En la esfera política existen muchos casos menos dramáticos análogos a tales situaciones, en los cuales un bien sustancial está en juego, un bien respecto del cual tenemos razones morales para asegurarlo para nosotros mismos y para otros, pero que puede en esas circunstancias ser asegurado mejor cediendo ante una autoridad coordinadora. Estos casos justifican renunciar a decidir por uno mismo, y no implican ninguna amenaza a la autenticidad de nuestra propia vida o a nuestra capacidad para llevar una vida autosuficiente y autónoma. Nada de esto niega que a menudo las dos preocupaciones, la que se satisface conformándose con las razones y la que lo hace actuando según el propio juicio, puedan ser radicalmente diferentes, y los argumentos a favor de la conformidad o a favor de la independencia pueden ser inconmensurables, con el (incómodo) resultado de que si uno está, entonces, sometido o no a la autoridad queda indeterminado.

La otra objeción a la condición de autonomía no se puede desestimar tan fácilmente. Debe ser enfrentada no con una refutación sino con una desviación. En efecto, la condición de independencia aporta poco a la resolución del problema. Ésa no es su tarea. Meramente enmarca la cuestión. Parte de la respuesta al desafío moral a toda autoridad está en la primera condición, que dice que la autoridad puede ser legítima si la conformidad con ella mejora la conformidad por uno mismo con la razón ${ }^{17}$. Ella proporciona la clave para la justificación de la autoridad: la autoridad ayuda a nues-

\footnotetext{
${ }^{16}$ Recurrí a la noción de razones de segundo orden para expresar tales situaciones. Ellas implican razones para actuar por una cierta razón, y la facultad de la razón se desprende de su función cuando nos conformamos con esa razón de segundo orden.

${ }_{17}$ Por razones de brevedad usaré esta y otras nuevas formulaciones similarmente inexactas de la primera condición.
} 
tra capacidad racional cuya función es asegurar la conformidad con la razón. Permite a nuestra capacidad racional alcanzar su propósito con más éxito. Estas observaciones expresan una manera de entender nuestra capacidad general de guiar nuestra conducta (y más ampliamente nuestra vida) por nuestro propio juicio. El propósito de esta capacidad general es permitirnos conformarnos con las razones que se nos presentan en cualquier momento dado. Es la conformidad alcanzada por el ejercicio del juicio propio. Valoramos la habilidad de ejercer nuestro propio juicio y de confiar en él para la acción, pero es una capacidad que valoramos por su propósito, que es, por su misma naturaleza, asegurar la conformidad con la razón. Esta tesis es completamente general. Cierto que el valor de muchas de nuestras capacidades no debe ser reducido únicamente al valor de su uso. Pero, incluso cuando su valor también refleja el valor de la libertad de usar nuestras capacidades o no ${ }^{18}$, su valor depende del valor de su uso con éxito.

El valor de nuestra capacidad racional, es decir, de nuestra capacidad de formarnos una opinión sobre nuestra situación en el mundo y de actuar bajo esa luz, deriva del hecho de que hay razones que debemos satisfacer y de que esta capacidad nos permite hacerlo. No es, sin embargo, nuestra única manera de conformarnos con las razones. Por ejemplo, estamos programados para estar alerta ante ciertos peligros y reaccionar a ellos instintivamente y sin deliberación, como cuando reaccionamos al fuego o al movimiento súbito en nuestra proximidad inmediata. En otros contextos hacemos mejor siguiendo nuestras emociones que razonando nuestro camino hacia la acción. Estos ejemplos sugieren que el valor primario de nuestra habilidad general de actuar por nuestro propio juicio deriva de la preocupación de conformarnos con razones, y esa preocupación puede ser satisfecha en una variedad de formas. Por consiguiente, no es sorprendente que nos encontremos con que también se satisface en formas que se aproximan a obedecer a la autoridad, tales como hacer votos, recibir consejo, vincularse a otros mucho antes del momento de la acción con una promesa a actuar de cierta manera, o confiar en artefactos técnicos que "toman decisiones por nosotros", como cuando ponemos despertadores, limitadores de la velocidad, etc.

Tanto el guiarnos por nuestras emociones como el guiarnos por nuestro juicio (sin ser necesariamente estas condiciones mutuamente excluyentes) son componentes de algunas actividades y relaciones que son valiosas en sí mismas, dando lugar a casos en los que la condición de independencia para la legitimidad no se satisface. De la misma manera, puede haber otras formas de actividad, actividades y empresas colectivas, que son valiosas en sí mismas y que inherentemente implican ceder a decisiones tomadas por otros. Las condiciones de legitimidad están abiertas a diferentes perspectivas sobre lo que es y lo que no es valioso o merece la pena. Ellas meramente establecen cómo las conclusiones sobre tales asuntos influyen en la cuestión de la autoridad.

Al postular que las autoridades son legítimas sólo si sus directivas permiten a sus súbditos conformarse mejor con la razón, vemos a la autoridad como lo que es: no

${ }^{18}$ De hecho, aun cuando podemos manipularnos a nosotros mismos, a través del abuso de drogas o de alguna otra manera, para perder, por un período corto o largo, el uso de nuestra capacidad racional, ésta no es una capacidad que podamos usarla o abstenernos de usarla a voluntad, como sí podemos hacerlo con nuestra capacidad para leer libros. 
una negación de la capacidad de la gente para la acción racional, sino simplemente un mecanismo, un método, a través de cuyo uso la gente puede alcanzar la finalidad (telos) de su capacidad de acción racional, aunque no a través de su uso directo. Esta manera de entender las cosas se refuerza por el hecho de que al seguir a la autoridad, igual que al seguir un consejo o al guiarse por cualquiera de los artefactos técnicos, nuestra autoconfianza última queda preservada, porque es nuestro propio juicio el que nos conduce a reconocer la autoridad de otro, igual que nos conduce a mantener nuestras promesas, seguir un consejo, usar artefactos técnicos y demás.

Por supuesto, la autoridad es especial en la manera en que restringe nuestra capacidad para actuar independientemente. La concepción de la autoridad como servicio expresa esta idea mediante la tesis de que las directivas autoritativas reemplazan a las razones en contra de la conducta que ellas exigen, suponiéndose que la autoridad está pensada precisamente para tener ella en cuenta esas razones contrarias al decidir emitir sus directivas. Los que están sometidos a la autoridad no tienen permitido cuestionar la sabiduría o la pertinencia de las directivas de la autoridad. Una descripción simplificada de algunas situaciones típicas explica esta idea. Hay razones con las que todos debemos conformarnos, por ejemplo sobre conducir de manera segura. En ausencia del Derecho (u otras directivas autoritativas) que nos diga cómo conducir (imponiendo límites de velocidad, semáforos, señales de tráfico, etc.), habríamos intentado conducir lo más seguro posible. El Derecho de tráfico está pensado para posibilitarnos conducir con más seguridad (o sea, para conformarnos mejor con las razones de fondo), y lo hace ordenándonos hacer cosas que de otra manera podríamos no haber hecho. Cuando el Derecho nos deja a nosotros las decisiones sobre la conducción, seguimos guiándonos por esas consideraciones de fondo. Pero cuando él interviene para exigir ciertas formas de conducir, estamos obligados a obedecerlo, y no se nos permite cuestionar su fuerza, aun cuando se nos permita, por supuesto, cuestionar su sabiduría y abogar por su reforma. Esto es, toscamente, lo que quiero decir cuando afirmo que las disposiciones jurídicas legítimas, y en general las directivas de las autoridades legítimas, reemplazan a las razones subyacentes que podrían militar en contra de las directivas autoritativas y las sustituyen por sus propios requerimientos ${ }^{19}$.

La fuerza de reemplazo de la autoridad es parte esencial de su naturaleza. No puede tener éxito como autoridad (o sea, éxito en mejorar nuestra conformidad con la razón) si no reemplaza a las razones de fondo. La función de las autoridades es mejorar nuestra conformidad con esas razones de fondo haciendo que tratemos de seguir sus instrucciones en lugar de las razones de fondo. Las autoridades no pueden hacer esto sin al menos la posibilidad de que sus directivas nos lleven a veces a actuar de manera diferente a como lo habríamos hecho sin ellas. En sí mismo, mientras que esto requiere que las directivas de la autoridad sean capaces de cambiar lo que debe-

\footnotetext{
${ }_{19}$ No deseo dar rienda suelta a un análisis excesivamente detallado, pero merece la pena advertir que hay dos tipos de razones afectadas por la tesis del reemplazo: primero, se reemplazan razones en contra de la conducta requerida por la directiva autoritativa. Segundo, se reemplazan razones que no necesariamente afectan a los pros y contras de comportarse como la directiva requiere, sino que militan en contra de la conveniencia de emitir la directiva. Estas razones pueden ser que la cuestión se debería dejar a la discreción individual, o que la directiva tendrá efectos colaterales indeseables que la hacen indeseable, y cosas por el estilo.
} 
mos hacer, todas las cosas consideradas, no especifica de qué manera impactan en lo que tenemos más razón para hacer. La tesis del reemplazo explica esto: refleja la idea de que las autoridades son capaces de funcionar de la manera descrita porque sus decretos son el producto de decisiones hechas por agentes que fueron puestos para determinar qué es lo que debemos hacer, y ordenarnos hacerlo. Ellas constituyen autoridades legítimas cuando al hacer eso alcanzarán de hecho el resultado de una mejor conformidad con la razón (respetando las razones que tengamos para determinar nuestras acciones mediante nuestro libre juicio). El hecho de que es así es como operan las autoridades indica que cuando ellas son legítimas sus decretos deben sustituir a las razones de fondo. Las reemplazan. ¿Cuánto es reemplazado? ¿Qué es lo que cuenta como razones de fondo? Ellas son las razones para cuya consideración está pensada la autoridad cuando emite sus directivas, siempre que, por supuesto, actúe dentro del ámbito de su poder legítimo.

La existencia del reemplazo de las directivas autoritativas muestra por qué la pregunta moral sobre el Derecho es una pregunta seria. Muestra qué hay de verdad en el dicho de que al aceptar la autoridad entregamos nuestro juicio a la autoridad. Al mismo tiempo la solución del problema teórico muestra que, a pesar de su carácter especial, la autoridad, cuando está sometida a las condiciones de la justificación normal y de la independencia, es tan sólo un caso más del mundo que nos enfrenta con razones para la acción. La perplejidad teórica decía: «¿cómo pueden las personas crear razones al actuar con la intención de hacerlo?». La respuesta es que esto es así cuando consideraciones que son independientes de la voluntad humana así lo determinan.

Una vez más vemos la analogía (así como la diferencia) entre la autoridad y las promesas. Ambas producen razones generadas por acciones diseñadas para hacerlo, un hecho que les da a ambas su aire de perplejidad, y ambas lo pueden hacer porque consideraciones independientes de la voluntad humana validarán tal creación de razones. Por consiguiente, al seguir a ambas seguimos a la razón, y así ejercemos nuestro juicio - aunque en ambos casos lo hacemos a un paso de distancia - al aceptar, mediante nuestro juicio, la fuerza vinculante de actos (promesas, directivas) que reemplazan nuestra libertad para actuar por algunas de las razones de fondo. Es verdad que sólo la autoridad implica aceptar las directivas de otro. Pero si las dos condiciones son correctas, incluso las directivas autoritativas, al igual que las promesas, son vinculantes porque y cuando mejoran nuestros poderes al capacitarnos para conformarnos con la razón mejor de lo que podríamos hacerlo sin ellas.

\section{REFINAMIENTOS Y ELABORACIONES}

Hasta aquí he intentado esbozar los perfiles de la concepción de la autoridad como servicio y explicar cómo lucha con dos problemas básicos sobre la autoridad. Su éxito al ocuparse de ellos es el principal argumento para creer que está en la dirección correcta. Pero para consolidarse la teoría tiene que ocuparse de todo un conjunto de dificultades adicionales. En esta sección examinaré brevemente una variedad de dificultades; reflexionar sobre ellas llevará a refinar la teoría, así como a exhibir algunas de sus fortalezas. 


\section{1. ¿Podemos estar sometidos a varias autoridades al mismo tiempo?}

Claro que podemos. La pregunta más difícil es si podemos estar sometidos a más de una autoridad con respecto al mismo asunto al mismo tiempo. La tesis de la justificación normal está basada en un contraste entre cómo actuaría yo si no estuviera afectado por la autoridad comparado con cómo actuaría yo al intentar seguir a la autoridad. En el contexto, esto es ambiguo. ¿Significa «cómo actuaría yo si no estuviera influido por ninguna autoridad»? ¿O significa «cómo actuaría yo si no intentara seguir esta autoridad en particular»? La primera pregunta permite la posibilidad de que estemos sometidos a varias autoridades al mismo tiempo y con respecto al mismo asunto. Así es como debe ser. Podemos estar sometidos a la autoridad de nuestros padres, de nuestras escuelas, y del Derecho, por ejemplo, al mismo tiempo, y con respecto a la misma cuestión.

Cuando están sometidos a varias autoridades con jurisdicciones similares o superpuestas, ciertos asuntos pueden estar regulados por sola una autoridad, mientras que las otras autoridades permanecen en silencio respecto a ellos. En esos casos debemos seguir a aquellas que emiten directivas sobre el asunto. Cuando diferentes autoridades se pronuncian sobre el mismo asunto, y sus directivas chocan, debemos decidir, haciendo máximo uso de nuestras habilidades, cuál es más fiable como guía. A menudo hay relaciones cooperativas entre autoridades. El Derecho reconoce la autoridad de escuelas y padres, por ejemplo, y les confiere autoridad jurídica, ordenando a las personas relevantes obedecerlos, o haciendo efectivas sus directivas mediante procedimientos jurídicos. Otras veces las autoridades pueden ser hostiles entre sí, ordenando a sus súbditos no obedecer, y en general no cooperar, con el funcionamiento de otras autoridades. En tales casos, la cuestión de si el poder de una autoridad dada comprende el de excluir la autoridad de otra ha de juzgarse de la manera en que juzgamos la legitimidad de su poder en cualquier materia, a saber, si nos conformaríamos mejor con la razón intentando seguir sus directivas que si no lo hacemos.

\subsection{Reemplazo y actuar por las mejores razones}

A menudo tenemos más de una razón suficiente para hacer algo. Una directiva autoritativa puede indicarnos hacer algo que debemos hacer de todas formas, por razones independientes. Por ejemplo, puedo haber prometido a un amigo conducir despacio, y el Derecho también me ordena conducir despacio. Si conduzco despacio, lo puedo hacer sólo por la promesa, no siendo consciente del Derecho o no preocupándome por obedecerlo; o puedo hacerlo únicamente por el Derecho; o por ambos; o aun por otra consideración que parece ser una razón poderosa, aunque puede no serlo.

Tales situaciones no suscitan ningún problema. Pero el Derecho implica un tipo diferente de sobredeterminación. Por ley no debemos matar, pero también tenemos una razón independiente para no matar, el respeto a la vida humana. Éste es un caso típico entre muchos. Otro tipo de sobredeterminación es algo diferente. Tenemos una razón independiente del Derecho para contribuir con nuestra parte en el coste del mantenimiento de los servicios de la comunidad. El Derecho impone un deber de 
pagar impuestos como una manera de hacerlo. Independientemente del Derecho, no tenemos una razón para pagar la suma precisa que debemos como impuesto. Pero una vez que el Derecho está allí tenemos dos razones, podemos decir, para pagar la suma que debemos como impuesto (aquí podemos dejar de lado que es probable que el Derecho tributario sirva también a otros propósitos). Una es nuestra obligación de obedecer al Derecho, la otra nuestro deber de contribuir al coste de los servicios de la comunidad.

En términos ideales, nos tendríamos que abstener de matar exclusivamente por respeto a la vida de las personas y de ninguna manera por respeto al Derecho. En términos ideales, debemos pagar nuestros impuestos porque lo debemos como nuestra parte en el coste de los servicios de la comunidad, así como porque el Derecho lo exige. ¿Es esto consecuente con la tesis del reemplazo?

Una comprensión adecuada del reemplazo elimina cualquier sospecha de la existencia de un problema. Una directiva autoritativa obligatoria no es sólo una razón para comportarse como ella ordena, sino también una razón excluyente, es decir, una razón para no seguir (o sea, no actuar por) razones que chocan con la regla. Así es cómo las directivas autoritativas reemplazan. Ellas excluyen confiar en razones contrarias, no todas las razones contrarias, sino aquellas que el legislador debió considerar antes de emitir la directiva. Estas razones excluyentes, por supuesto, no excluyen basarse en razones para comportarse de la misma manera en que la directiva lo exige. Piénsese en ello: la autoridad mejora nuestra conformidad con la razón desplazando lo que haríamos sin ella, cuando actuar sin ella no nos haría conformar con la razón. De esta manera, asumiendo que tiene completo éxito en su tarea, no necesita frenarnos y no nos frena si seguimos las razones del lado vencedor de un argumento. Sin embargo, si ha de mejorar nuestra conformidad con la razón, debe desplazar nuestra inclinación a seguir a razones del lado perdedor del argumento. Por lo tanto, el reemplazo excluye sólo razones que chocan con la directiva de la autoridad.

Así que cuando una acción es correctamente requerida por la autoridad (es decir, cuando hay razones concluyentes a su favor, independientemente de la intervención de la autoridad), podemos (en ambos sentidos) hacer lo requerido o bien porque así se nos ha requerido, o bien por las razones que justifican el requerimiento, o por ambas cosas. A veces, como en el caso de la prohibición de matar, hacer lo requerido por la autoridad por razones poderosas diferentes al hecho de que la conducta fue así requerida por la autoridad, es la mejor opción. Habrá otros casos, por ejemplo, casos en los que la directiva emitida por la autoridad está equivocada o es injustificada. Requiere alguna acción cuya realización, aunque apoyada en algunas razones independientes de la autoridad, no está suficientemente fundada para requerir esa acción; no lo está si la directiva que la requiere se ignora. Esto puede ser consistente con que la directiva sea para nosotros vinculante. Incluso las autoridades legítimas cometen errores. En tales casos debemos conformarnos con su directiva, y el caso ideal es uno en el que lo hacemos porque nos lo ha requerido la autoridad y no por las otras razones que respaldan la acción.

El ejemplo del impuesto era diferente porque no tenemos una razón independiente del Derecho para pagar exactamente lo requerido por el Derecho ni para pagarlo a esa precisa autoridad, aunque una vez que la ley está en vigor la razón que justifica 
aprobarla es una razón para hacer lo que ella requiere, lo cual es distinto del deber general que tenemos de obedecer a una autoridad legítima. En tales casos la mejor opción es actuar por ambas razones, o sea, tanto por el Derecho como por las razones de fondo para actuar.

¿En qué sentido estas opciones son las mejores? Todo lo que se nos exige es que nos conformemos con la razón, y no importa por qué razón, o razón imaginaria, lo hagamos. Sin embargo, no sólo lo que hacemos sino por qué lo hacemos dice algo acerca de nosotros. Es respecto de tales juicios, los juicios sobre el agente, sobre qué tipo de persona es, cómo se conduce y demás, que importan las razones reales que lo llevaron a la acción.

\subsection{Razones en conflicto}

Las directivas autoritativas no siempre son razones concluyentes para la conducta que requieren. Pueden ser derrotadas por razones contrarias o por directivas contrarias. Las razones que pueden derrotarlas son aquellas que ellas no excluyeron. La cuestión es de alguna importancia cuando se considera al Derecho. Típicamente, una regla jurídica no excluye a otra del mismo rango (en el sentido en que tienen rango diferente las reglas constitucionales, la ley, los reglamentos administrativos y la jurisprudencia del common law). Las reglas jurídicas excluyen muchas consideraciones no jurídicas, aunque los sistemas jurídicos típicamente permiten que algunas cuenten y, a veces, que desplacen a los requerimientos jurídicos. Pero no excluyen otras reglas jurídicas del mismo rango. Sostendré que las reglas jurídicas constituyen razones prima facie para la conducta que prescriben.

Cuando las reglas jurídicas entran en conflicto entre sí, ¿cómo tiene que decidirse el resultado? Hay muchos mecanismos a los que recurre el Derecho buscando ayuda. El problema surge cuando no hay ningún mecanismo formal disponible o suficiente. La pregunta es si los méritos relativos de las razones de fondo, aquellas a favor y en contra de cada una de las reglas, cuentan en la correcta determinación de cada uno de tales conflictos. Parece irrazonable ignorar estas razones de fondo, ya que ello no deja más opción que considerar que todas las reglas del mismo rango constitucional cuentan de la misma manera, y en el mismo grado, en el resultado. Dado que una regla puede ser trivial, por ejemplo, alguna regulación de un impuesto menor, mientras que otra puede ser central en la protección de derechos fundamentales, sería irrazonable considerar que tienen igual importancia. No obstante, la tesis de que las directivas autoritativas excluyen basarse en consideraciones contrarias ¿no significa que a uno no le está permitido evaluar la verdadera importancia de una regla, lo cual implicaría evaluar razones a favor y en contra de ella, y ellas incluyen razones a favor y en contra de la conducta que prescribe?

Sin embargo, la tesis del reemplazo implica rechazar ambas alternativas. Como fue mencionado, excluye la referencia a las consideraciones de fondo, y así impide una evaluación apropiada de la importancia de la regla. No obstante, no se sigue que todas las reglas del mismo rango constitucional tengan que ser vistas como teniendo la misma importancia. Igual que la autoridad hace el Derecho, también indica, o al menos puede indicar, la importancia que tiene a sus ojos. Son varias las maneras de hacerlo, la mayo- 
ría implícitas, algunas más explícitas, como los preámbulos y otros instrumentos legislativos. Otras indicaciones están implicadas en el lenguaje en el cual se expresó el Derecho y en el contexto de su legislación. En la medida en que la práctica judicial instruye a los tribunales a acudir a estos mecanismos, están reconocidos como jurídicamente vinculantes y tienen existencia autoritativa.

No se niega que sea improbable que tales consideraciones resuelvan todos las problemas que puedan surgir sobre la importancia de cada regla jurídica. Tampoco todos los problemas que surgen de conflictos entre reglas jurídicas pueden ser solucionados priorizando a unas sobre otras. A menudo, en lugar de seguir una regla en lugar de la otra, los conflictos prácticos deben resolverse encontrando la opción que satisface a las reglas en conflicto en el mayor grado posible. Ello se sigue de la naturaleza de la racionalidad práctica, que requiere que, cuando no es posible conformarse completamente con las razones, hay que conformarse a ellas en el grado más alto posible. Esto requerirá que los tribunales enfrentados con conflictos de este tipo encuentren tal resultado óptimo, lo cual implicará una comprensión del propósito de las reglas en conflicto. Ya vimos que esto es consistente con la concepción de la autoridad como servicio.

Aun así, de manera no infrecuente, en diversos conflictos entre reglas jurídicas el Derecho no contiene recursos para resolver el conflicto. Es indeterminado respecto a la cuestión, dejando normalmente tales decisiones a la discreción de los jueces, o sea, a su juicio sobre el mérito real de las diferentes reglas, un juicio que va más allá de lo que el Derecho determina.

\subsection{Razón y cognoscibilidad}

Es cuestión discutida si un factor no conocido por algunos agentes, o no cognoscible por ellos, puede no obstante constituir una razón para esos agentes. Cualquiera que sea la verdad sobre esa cuestión general, hay razones independientes para pensar que alguien o alguna institución puede ser autoridad sólo si el hecho de que se cumplen las dos condiciones puede ser conocido por sus súbditos. El valor de estar sometido a una autoridad es que ofrece una manera de mejorar nuestra conformidad con la razón. Uno lo logra conformándose con las directivas de la autoridad y (circunstancias especiales aparte) uno puede fiablemente conformarse sólo si tiene creencias fiables respecto de quién tiene autoridad legítima y de cuáles son sus directivas. $\mathrm{Si}$ uno no puede tener creencias fiables de que un cierto organismo cumple las condiciones de legitimidad, entonces su creencia en su autoridad es fortuita, y no puede (de nuevo, circunstancias especiales aparte) ser fiable. Por consiguiente, para cumplir su función, la legitimidad de una autoridad debe ser cognoscible para sus destinatarios.

$\mathrm{Al}$ exponer este argumento asumí que, siempre que uno pueda formarse creencias fiables de que se cumplen las condiciones para la legitimidad, también puede uno tener conocimiento de que se cumplen. También estaba basándome en el hecho de que, generalmente hablando, la única manera fiable de conformarse con la autoridad es teniendo una creencia fiable de que es una autoridad, y que, por tanto, debe ser obedecida. Asumir esto ayuda a definir con mayor precisión qué es lo que ha de darse 
para que la legitimidad sea cognoscible. Dado que el propósito es mejorar la conformidad con la razón, hay al menos una medida tosca de cuán importante es tal mejora. Cuanto más importante sea, más indicado está realizar extensas indagaciones acerca de las maneras de lograrlo. El grado indicado de indagación establece el límite de la cognoscibilidad: es cognoscible si una indagación de ese tipo produciría ese conocimiento.

Realizamos tales evaluaciones todos los días de la semana. Regularmente necesitamos decidir cuán lejos seguir una indagación con la esperanza de llegar a una conclusión más fiable o más matizada acerca de cuál es en varias ocasiones el curso de acción correcto. Cuando el asunto es de importancia extendemos nuestras indagaciones y deliberaciones mucho más allá de lo que lo hacemos cuando la cuestión es relativamente insignificante. El mismo tipo de consideraciones se aplica para establecer la existencia de autoridades. Cuánto cabe esperar que mejore nuestra conformidad con la razón, y cuán importante es el asunto en cuestión, son las variables que establecen qué indagación es razonable emprender. Cuando una indagación razonable no revelará la justificación de la autoridad, esa justificación, si es que existe, no es cognoscible. Se sigue que las personas no están sujetas a ninguna autoridad con respecto a esos asuntos.

Este argumento es usado aquí para establecer no meramente que no es racional, o que no vale la pena, continuar con la indagación sobre la existencia de ciertas razones, sino que esas razones, las directivas autoritativas, no existen. No hay autoridad sobre el asunto porque, para existir, las autoridades deben ser cognoscibles. Esta expansión del argumento no es sorprendente. La concepción de la autoridad como servicio hace que la legitimidad de las autoridades dependa primariamente de su valor para alcanzar algo más allá de ellas, a saber, la conformidad con razones de fondo que existen independientemente de ellas. En general no tenemos ninguna razón para seguir a los medios a menos que valga la pena seguirlos, dado el coste de hacerlo en relación con la importancia de los fines. Para dar un ejemplo simple: supongo que puedo hacer que tú me des cinco libras dándote diez libras a condición de que tú me des cinco libras a cambio. Pero (circunstancias especiales aparte) no tengo ninguna razón para seguir ese medio para ese fin, ninguna razón en absoluto. No es meramente el caso de que tengo una razón que es derrotada por el coste de seguir ese medio. El caso de la autoridad no es exactamente el mismo, pero es análogo: el obedecer a Jane, digamos, podría ayudarme mejor a conformarme con las razones que se me aplican. Sin embargo, no puedo saberlo sin llevar a cabo una indagación que sería irracional realizar. Se sigue que no tengo ninguna razón para obedecer a Jane, y de ahí se sigue que Jane no tiene autoridad sobre mí.

\subsection{La clase más pequeña}

Hay otras limitaciones epistémicas sobre las condiciones de legitimidad. Ellas restringen la aplicación de las condiciones sustantivas. Por ejemplo, supongamos que podemos establecer que nos conformaremos mejor con la razón si seguimos a la autoridad en asuntos de una cierta área, pongamos, los asuntos de los que tratan las regulaciones sobre seguridad en el trabajo. ¿Se extiende el poder de la autoridad sobre 
toda el área o se limita tan sólo a una parte de la misma? La condición de la justificación normal se puede tomar como que significa que tiene autoridad sobre toda el área. Pero ello tropieza con la objeción de que el área puede ser artificialmente expandida (p.e., agregando a la misma la seguridad en el hogar) sin ninguna razón para creer que estaremos mejor en las zonas expandidas (p.e., podemos ser nosotros mismos mejores jueces sobre la seguridad en nuestros hogares que cualquiera que sea la autoridad sobre la seguridad en el trabajo). El área total expandida aún puede cumplir ambas condiciones de legitimidad simplemente porque el área más estrecha las cumple, y las desventajas de la expansión no son lo suficientemente malas como para anular el argumento a favor de la autoridad.

La solución a este acertijo consiste, creo, en que una persona u organismo tiene autoridad con respecto a cualquier área si esa persona u organismo cumple las condiciones con respecto a esa área, y no hay ninguna parte discernible del área con respecto a la cual se pueda conocer que la persona u organismo falla en las condiciones.

\subsection{Las cargas de la indagación y de la decisión}

La segunda condición de legitimidad, la de la independencia, tiene como premisa la idea de que es importante que las personas decidan por sí mismas cómo dirigir sus vidas, y que, especialmente en algunas áreas, deben hacerlo con sólo limitada confianza en el consejo directo, más aún en el caso de órdenes, de otras personas. No vivimos totalmente como personas autónomas si no decidimos por nosotros mismos. No se sigue, por supuesto, que siempre disfrutemos al hacerlo. Algunas personas encuentran duro de llevar la carga de la decisión. Andan con rodeos, se deprimen, se sienten oprimidos y presionados y, por supuesto, a menudo deciden imprudentemente, con frecuencia casi arbitrariamente, con el fin de liberarse de la carga decidir.

No todos padecen una aversión a tomar decisiones y a asumir responsabilidades, pero la mayoría de las personas siente la carga. Estamos tentados a pensar que no se es un agente responsable si no se la siente, pues ello mostraría una falta de seriedad sobre las propias acciones. Sea esto como fuere, todos tenemos que soportar la carga de la indagación. Ella demanda nuestra atención, energía, tiempo y recursos; puede imponer tensiones en nuestras relaciones con otros, etc. Cierto que el proceso de indagación con un propósito, de abrirse camino hacia una decisión, también puede disfrutarse y ser gratificante en sí mismo. Pero dado que su propósito y justificación primarios es que contribuye a una buena decisión, no se puede esperar que la gratificación se equipare a las cargas, y a veces las cargas superan ampliamente a las gratificaciones.

Hay maneras de reducir las cargas de la decisión y de la indagación, y algunas de ellas implican desplazar la carga hacia otros. La práctica de confiar en el asesoramiento de un profesional ha crecido en los tiempos recientes, quizás en paralelo con un declive de la familia como fuente de consejo y apoyo en la toma de decisión. Someterse a la autoridad es una manera de reducir las cargas. Sólo puede estar justificado si es consistente con la condición de independencia de la legitimidad (aunque cuando la vulnerabilidad psicológica a la carga es extrema puede estar justificado mitigar la condición para aliviar la carga). La condición de la justificación normal, sin embargo, 
se entiende mejor, en sentido amplio, como permitiendo que el cumplir con la carga de la decisión y la indagación sea uno de los beneficios que las autoridades pueden aportar.

\subsection{Respeto y otras razones}

Podemos acomodar las cargas de la decisión y de la indagación en una teoría de la autoridad legítima, o bien a través de una lectura apropiada de las dos condiciones, o bien reconociendo a estas cargas como factores adicionales que influyen en la legitimidad, factores que modifican o se añaden a las dos condiciones. No creo que sea posible enumerar exhaustivamente las consideraciones que puedan incidir en la legitimidad de la autoridad o, respecto a eso, en la justificación de cualquier otra institución normativa que esté ampliamente aceptada y arraigada en prácticas sociales. Tales instituciones a veces sí tienen propósitos o sentidos centrales; pero, una vez que son reconocidas y seguidas en la práctica, se enredan con otras prácticas y preocupaciones que, sin desviarlas de su justificación primaria, las conducen a acumular propósitos y razones justificativas adicionales.

Un factor adicional de este tipo surge a partir del modo en que, en muchas sociedades, algunas autoridades se convierten en la expresión visible primaria de instituciones a las que ellas pertenecen y en cuyo nombre funcionan. Las instituciones políticas y jurídicas con autoridad jurídica son un caso de este tipo. En muchos países las autoridades jurídicas superiores se identifican con el Estado o el país o la nación, y hablan en su nombre. Cuando esto es así, el respeto por y la identificación con el Estado, país o nación se puede expresar en el respeto por esa autoridad jurídica, y eso a su vez toma la forma (entre otras) de la confianza en estas instituciones, aceptando por confianza en ellas que tienen autoridad para hacer lo que hacen, sin cuestionar demasiado estrechamente su conducta para ver si exceden su autoridad, etc. La confianza es una señal general de respeto y una señal natural. Si el respeto por el Estado, país o nación es deseable, que a veces lo es, y si es apropiado, dadas las circunstancias de la sociedad en cuestión, que ese respeto se exprese a través del respeto y la confianza en sus instituciones jurídicas, entonces también es aceptable cierta relajación en la vigilancia sobre las dos condiciones de legitimidad. Es decir, en tales casos, aunque las condiciones en sí mismas no se ven afectadas, estaría justificado que la gente mantuviera que el gobierno tiene autoridad basándose en pruebas que no serían suficientes para alcanzar tal conclusión si no fuera por la confianza que tienen en el gobierno.

No sostengo que las personas tengan un deber de confiar en y respetar a su gobierno de esa manera. Eso sería como afirmar que tienen un deber de tener a alguien como su amigo. El respeto del que estamos tratando aquí no es el respeto básico que debemos a toda persona. Es el respeto que surge de la identificación con el país, y nadie tiene ningún deber de identificarse con ningún país. Lo que afirmo es simplemente que esa actitud es, a veces (cuando se reúnen ciertas condiciones morales), apropiada.

¿Muestra esto que, a veces, las personas que confían en el gobierno están justificadas al creer que el gobierno tiene autoridad cuando no la tiene; o muestra esto que, a veces, el gobierno tiene autoridad sobre tales personas, aun cuando no tiene auto- 
ridad o sólo tiene una autoridad más limitada sobre las personas que no confían en él? Se puede argumentar en los dos sentidos. Por un lado, se puede pensar que es deseable separar las consideraciones epistémicas de las sustantivas y tener una teoría que tienda a hacer a la autoridad gubernamental independiente de factores individualmente variables tales como la confianza que es resultado de la identificación con el país. Por otro lado, como vimos, la concepción de la autoridad como servicio sí incorpora elementos epistémicos en las condiciones de la autoridad y, como veremos, permite una considerable variabilidad en la extensión de la autoridad gubernamental sobre la población sobre la que pretende autoridad. De modo que puede ser que la mejor perspectiva sea considerar que la identificación afecta a las condiciones de legitimidad y no meramente a las ocasiones en las cuales está justificado creer que esas condiciones se cumplen. De esta forma, la teoría es más cercana a actitudes familiares (y racionales) que la gente tiene hacia la autoridad.

\subsection{Razones preexistentes y concretización}

La teoría puede parecer indebidamente restrictiva. Puede parecer que excluye todo poder a los gobiernos para mejorar las condiciones económicas de sus ciudadanos. Por ejemplo, la autoridad puede hacerlo imponiendo tributos y usando los ingresos para subvencionar la formación profesional, lo cual es útil para el pleno empleo y para el desarrollo económico. Ni yo ni otros habitantes tenemos razones para imponer tributos o para subvencionar la formación en el país. Pero ésa es una percepción equivocada. En la medida en que los habitantes de un país tienen razón para mejorar su propia situación económica, tendrán razón para hacerlo mediante una autoridad común en aquellas materias donde esa autoridad será capaz de alcanzar esa meta mejor de lo que ellos podrían hacerlo actuando independientemente de ella.

¿Significa esto que tengo razones para aumentar los impuestos? No necesariamente, pero la pregunta se origina al pasar por alto el hecho de que típicamente las razones no vienen por separado, más bien se presentan entrelazadas, anidadas. Típicamente, tenemos una razón porque conformarnos a ella es una manera de satisfacer otra razón. Las razones más generales se aplican como un estándar de fondo a nuestras actividades, y se ven menos afectadas por el cambio en las circunstancias; mientras que las razones más específicas que anidan en ellas tienden a aplicarse durante períodos más cortos, y dependen de condiciones que a menudo están sujetas al cambio. Mi razón para mejorar mi situación económica es un ejemplo de una razón relativamente general, que no es probable que desaparezca hasta mi jubilación o incluso después, aunque su urgencia y fuerza pueda cambiar con el tiempo. Una razón para cambiar de empleo puede derivar de ella. Puedo tener razones para cambiar de empleo en orden a mejorar mi condición económica. Pero es una razón más a corto plazo, que puede desaparecer si, por ejemplo, mi patrón actual me ofrece un ascenso, o por otras circunstancias.

Las personas que tienen asignada la tarea de ayudarnos lo hacen conformándose con o realizando algunas razones que se nos aplican, razones que nosotros mismos tenemos. Estas razones tienen otras anidadas en ellas, que establecen formas de realizarlas. Pero esas razones anidadas no tienen por qué ser razones para nosotros. Es 
decir, quienes nos ayudan pueden tener buenos fundamentos para perseguir las metas establecidas por razones que se nos aplican en formas que no están abiertas a nosotros. En efecto, como lo ilustra la concepción de la autoridad como servicio de la autoridad, pueden tener asignada la tarea de ayudarnos precisamente por eso. A través de su intervención nosotros adquirimos nuevas formas de realizar las metas establecidas por las razones generales de fondo, y por ello nuevas razones para llevar a cabo las acciones que las realizarán.

Existen otras maneras en que la flexibilidad de la concepción de la autoridad como servicio puede ser subestimada. Al dar los ejemplos que siguen no deseo avalar su fuerza. Tan sólo los menciono para ilustrar el poder de la concepción de la autoridad como servicio. Por ejemplo, alguien puede creer que la gente, los miembros de un cierto grupo, tienen un deber, quizás un deber religioso o un deber de lealtad originado en algunas circunstancias históricas, de obedecer a alguna persona o institución. En ese caso la tesis de la justificación normal se satisface fácilmente. Al obedecer a esa persona o institución se está cumpliendo con ese deber. O supóngase que los miembros de un cierto grupo, quizás un grupo étnico, tienen un deber de obedecer a alguien que puede ordenar la lealtad del grupo, una especie de deber nacional para la gloria de la nación. Nuevamente, si alguien puede ordenar la lealtad del grupo, entonces esa persona satisfará las condiciones de tener autoridad bajo la concepción de la autoridad como servicio. O supongamos que se tiene un deber de obedecer a quien gane la lotería; de nuevo, las condiciones de la concepción de la autoridad como servicio se cumplirán respecto a cualquiera que gane la lotería. Algunas personas creen que uno tiene un deber de obedecer a cualquiera que sea elegido por la mayoría. Una vez más, ése no es ningún problema para la concepción de la autoridad como servicio. Si eso es así, simplemente muestra que las condiciones de la concepción de la autoridad como servicio se cumplen con respecto a cualquiera que sea elegido de esa manera ${ }^{20}$.

\subsection{Coordinación y meta-coordinación}

Un factor importante, si no el principal, en el establecimiento de la legitimidad de las autoridades políticas es su capacidad para asegurar la coordinación. Algunos autores, al comentar este hecho, han ido más allá y han sostenido que: a) la única (o la única principal) función de las autoridades políticas es coordinar la conducta de los sometidos a ellas para el logro de algunos bienes; $b$ ) la coordinación, estando asegurada vía una convención de tipo Lewis, no requiere una autoridad con un derecho a gobernar: todo lo que requiere es la capacidad de destacar ciertos resultados de la

${ }^{20}$ No es, por supuesto, ningún accidente que mi teoría de la autoridad no haga ninguna referencia especial a la autoridad democrática. No creo que la democracia sea el único régimen que pueda ser legítimo, ni que todos los gobiernos democráticos sean legítimos. Esto no es decir que los gobiernos democráticos no tienen, en muchos países, pretensiones únicas de disfrutar de alguna autoridad cualificada o limitada, o bien a través de su capacidad para producir resultados beneficiosos o bien por su capacidad para expresar la existencia de las personas como agentes libres y autónomos, o por cualesquiera otros valores a los que sirvan. Me parece, sin embargo, de vital importancia no caer presos de la muy abusada retórica democrática actual, y mantener una perspectiva esclarecida y crítica sobre la naturaleza de las instituciones democráticas, y que debemos preservar nuestra capacidad de reconocer las limitaciones de los regímenes democráticos así como la posibilidad de que los que pasan por regímenes democráticos carezcan completamente de legitimidad. 
coordinación; y c) se sigue que las autoridades políticas, como tales, no gozan de un derecho a gobernar.

Perspectivas como ésas pasan por alto un buen número de hechos que son centrales para el funcionamiento de las autoridades políticas legítimas. Primero: que ellas pueden satisfacer la tesis de la justificación normal no sólo asegurando la coordinación, sino también teniendo un juicio más fiable sobre las mejores opciones, dadas las circunstancias, y que, en sus actividades normales, pericia y coordinación están indisolublemente mezcladas. Segundo: que la coordinación que las autoridades políticas deben asegurar, y que a menudo aseguran, raras veces es la clase de coordinación que constituye la solución a un problema de coordinación de tipo Lewis. Coordinar las acciones de muchos agentes no significa nada más que hacerlos, o capacitarlos para, actuar de manera tal que todos jueguen diversos roles en algún plan de acción posible que es probable que produzca algunos resultados buscados. Este tipo de coordinación generalmente no se puede lograr vía una convención de tipo Lewis. Tercero: una razón para esto es que la necesidad de coordinación y los medios para alcanzarla no son de manera necesaria generalmente conocidos y a menudo son objeto de controversia. Cuarto: que, dado que las metas que las personas realmente tienen no necesariamente son deseables, la coordinación dirigida a asegurar esas metas tampoco es necesariamente deseable. Los esquemas coordinados de acción que las autoridades políticas deben perseguir son aquellos con los cuales las personas deben estar comprometidas, o los que se necesitan para asegurar metas que la gente debe tener, que no siempre son las metas que de hecho tienen. Quinto: que típicamente, cuando la autoridad política es por otros motivos legítima y tiene un éxito razonable, también será correctamente considerada, al menos en algunas áreas, una autoridad en la cuestión de segundo orden de cuándo hay coordinación.

\section{LA OBJECIÓN DE LA CUALIFICACIÓN}

Una posible reacción a la concepción de la autoridad como servicio es que no da en el blanco. Describe las condiciones bajo las cuales una autoridad es una autoridad suficientemente buena. Articula tests para el éxito de las autoridades. Pero no explica lo que es ser una autoridad. Describe las condiciones que han de darse para que una autoridad sea capaz de desempeñar sus tareas con éxito, pero no es ni puede ser el caso que todo aquel que pueda desempeñar bien una tarea tenga esa tarea. No todo aquel que puede ser un buen primer ministro de un país es el primer ministro de ese país, no todo aquel que puede ser un buen maestro en la escuela primaria de mi barrio es maestro en esa escuela. Por otra parte, nadie es primer ministro o maestro tan sólo en virtud del hecho de que pueda realizar bien la tarea. Tiene que pasar algo más para que la tarea les sea asignada, para hacer que ella sea su tarea.

Para evaluar este punto debemos contrastar la autoridad teórica y la autoridad práctica. Las autoridades teóricas son expertos cuyo conocimiento y comprensión de la materia sobre la cual son autoridades es excepcionalmente amplia y notablemente sistemática y segura, lo cual los hace guías fiables en esas materias. Su palabra es una razón para sostener ciertas creencias y desechar otras. En eso, es como el testimonio: los relatos de los testigos sobre los acontecimientos sobre los cuales informan. Pero 
el asesoramiento de los expertos es muy distinto del testimonio de los testigos. En primer lugar, normalmente su consejo no informa acerca de sus creencias basadas en su percepción o del contenido de sus propias experiencias. (Las excepciones son casos en que lo que vemos es difícil de comprender, donde los expertos pueden ser útiles para decirnos lo que vemos nosotros y ellos.) Más bien, informan sobre las creencias que se infieren, las conclusiones que sacan de los datos derivados de su propia experiencia o de la de otros. En segundo lugar, y como corolario, su consejo no depende de su posición ventajosa en relación con la cuestión que está en consideración: a diferencia del testimonio de los testigos, los peritos no necesitan haber estado en el lugar adecuado en el momento preciso y haber visto o de alguna manera haber sido testigo de los acontecimientos sobre los que informan. Ellos derivan sus conclusiones no de la observación, lo cual requiere una posición ventajosa, sino de inferencias a partir de las pruebas, incluida la testifical, y eso no requiere gozar de una posición privilegiada o ventajosa en relación con los acontecimientos sobre los que aconsejan. Como resultado, mientras que el testimonio sólo se refiere a acontecimientos del pasado, los expertos también pueden predecir acontecimientos futuros.

Estas diferencias dan cuenta de las diferencias normativas entre testigos y expertos. Con los testigos todo lo que tenemos que hacer es evaluar la fiabilidad de su información: la calidad de su vista, las condiciones meteorológicas, su atención en ese momento, su distancia de los acontecimientos relatados, etc. Con los expertos normalmente no se suscita ninguna de estas cuestiones. Lo que cuenta es su habilidad para extraer conclusiones a partir de los datos o pruebas. A menudo es el conocimiento de la teoría, digamos de alguna teoría científica, y otras veces es la amplitud de su experiencia y la profundidad de su comprensión lo que le otorga sus credenciales como expertos, o sea, como personas que de manera fiable pueden inferir una cosa de otra. Una vez que su autoridad como expertos queda establecida, se sigue que nuestras evaluaciones inexpertas sobre los mismos datos no pueden desafiar a las de ellos de manera fiable. Veo un trozo de carne en la carnicería, y su color me hace pensar que no es fresca. Pero no tengo experiencia o teoría en la que apoyarme. Mi amigo experto me tranquiliza diciéndome que la carne es fresca, y yo cedo sin más. Si acepto la especialización de mi amigo, en comparación con la mía, no tengo otra opción. El consejo teórico reemplaza a las razones para creer en las cuales de otro modo me habría apoyado. Igual que con cualquier autoridad práctica, el valor de una autoridad teórica es hacer posible que me conforme con la razón, en esta ocasión con una razón para creer, mejor de lo que yo, de otro modo, pudiera hacerlo. Esto exige aceptar el consejo experto y permitirle reemplazar mi propia evaluación de los datos. Si no lo hago, no me beneficio de él.

La autoridad teórica se parece a la autoridad práctica en su valor (mejorar la conformidad con la razón) y en que reemplaza, así como en ser relacional, tanto con respecto a quien tiene que tomar la palabra de una autoridad como autoritativa como con respecto a la materia: es posible que yo deba tomar la palabra de este experto como autoritativa porque él sabe mucho más que yo, pero tú no tienes ninguna razón para hacer lo mismo, ya que tú sabes tanto como él en esta materia.

No obstante estas similitudes, hay diferencias significativas entre autoridades teóricas y prácticas. Apunté que, a diferencia del testimonio, alguna pericia puede ser la base de predicciones de acontecimientos futuros. Pero la pericia no puede cambiar 
nada. La capacidad de las autoridades prácticas para mejorar la coordinación, factor completamente ausente en las actividades de las autoridades teóricas, las hace estar sujetas a razones derivadas ${ }^{21}$ para asegurar las metas preexistentes en formas que de otro modo no serían posibles. Ellas pueden, como resultado, cambiar las cosas en el mundo.

Además, y casi no hace falta decirlo, las autoridades teóricas, los expertos, no pueden ordenarnos creer una cosa $u$ otra, y no pueden imponer deberes de creer; la naturaleza de las creencias y de la formación de creencias excluye tales deberes. La formación de creencias, igual que las acciones, responde a razones, pero sólo las acciones, y no la formación de creencias, involucran a la voluntad. Los deberes existen sólo cuando (pero no siempre incluso entonces) la respuesta a la razón implica a la voluntad.

Estas cuestiones están asociadas con importantes diferencias idiomáticas. Por ejemplo, algunas personas son autoridades en los métodos de cultivo del siglo XVIII, pero no tienen autoridad sobre nadie. Yo no sé nada sobre los métodos de cultivo del siglo XVIII, y debo tomar lo que ellos digan como autoritativo, pero no tienen autoridad sobre mí. De manera similar, la noción de autoridad legítima está limitada a la de autoridad práctica. Las personas pueden ser o no ser expertos o autoridades en los métodos de cultivo del siglo XVIII. Pero no pueden ser autoridades de facto o autoridades legítimas en el asunto. Finalmente, sólo respecto de cuestiones prácticas podemos decir que alguien tiene autoridad o que carece de ella. En cuestiones teóricas, alguien o es o no es una autoridad, pero nadie tiene autoridad.

¿Qué tienen estas cosas que ver con la crítica de la concepción de la autoridad como servicio, con la afirmación de que confunde un análisis de cuándo una autoridad es buena en lo que está haciendo con un análisis de lo que es ser una autoridad? A primera vista, pueden sugerir que la crítica es correcta respecto de las autoridades prácticas, pero equivocada sobre las autoridades teóricas.

Dado que las autoridades teóricas no pueden poseer o carecer de legitimidad, y no pueden imponer deberes (ni siquiera deberes para creer), ellas no pueden requerir una condición adicional más allá de las de la concepción de la autoridad como servicio. Si ellas están cualificadas como autoridades, ellas son autoridades. En realidad, ni siquiera la condición epistémica en la que antes reparamos, a saber, que su posesión de autoridad sea cognoscible por aquellos sobre quienes tiene autoridad, es aplicable a las autoridades teóricas, que no tienen autoridad sobre nadie. El mayor experto en los métodos de cultivo del siglo XVIII puede ser un solitario estudioso desconocido para la comunidad académica y no reconocido por nadie. Aun así, es una autoridad, tan sólo en virtud de su conocimiento sobre la materia. No se necesita nada más ${ }^{22}$. De esta manera, la objeción fracasa con respecto a las autoridades teóricas.

\footnotetext{
${ }^{21}$ Nótese que no es tan sólo que las autoridades crean nuevas razones emitiendo directivas. Esto también es verdadero en el caso de las autoridades teóricas. Su existencia misma crea oportunidades, y por eso las somete a nuevas razones derivadas, razones para satisfacer de nuevas maneras las razones previamente existentes.

${ }^{22}$ Por supuesto, normalmente no podemos saber que él es una autoridad a menos que alguien más lo compruebe. Pero parece que la implicación de que nadie que sea totalmente no reconocido puede ser una autoridad es mejor adscribirla a la pragmática del discurso.
} 
Las autoridades prácticas, por otro lado, imponen deberes a la gente. Tienen autoridad sobre las personas. Tienen poderes normativos sobre las personas. Para ser autoridades, dice el argumento, necesitan algo más que la capacidad de funcionar bien. Necesitan ser hechas autoridades, no necesariamente siendo designadas para la tarea, pero se tiene que dar algo parecido a una designación.

Sin embargo, la admisión de que la objeción fracasa con respecto a las autoridades teóricas me parece que demuestra que fracasa completamente. Es implausible pensar que lo que es un análisis acertado de lo que es ser una autoridad en cuestiones teóricas no contribuye en nada a la comprensión de la noción de autoridad, de lo que es tener autoridad práctica. Posiblemente, las diferencias entre los dos tipos de autoridad significan que es un análisis acertado de uno de los tipos, y sólo un análisis parcial del otro. Pero es implausible afirmar que no tiene nada que ver con el análisis del otro tipo. Hay otra razón para dudar de la objeción. Parece implausible pensar que uno puede ser una autoridad legítima sin importar lo malo que uno sea al actuar como autoridad. Si el valor primario de la autoridad, incluida la autoridad práctica, es mejorar la conformidad con la razón, es implausible pensar que alguien que no contribuye en nada al respecto, alguien que de hecho nos hace actuar más en contra de la razón de lo que nosotros lo haríamos si no hubiéramos intentado seguirle, pueda tener autoridad legítima.

Por consiguiente, podemos rechazar la objeción. Pero otra objeción más modesta está a la vuelta de la esquina. Sostiene que con respecto a las autoridades prácticas, dada su capacidad de cambiar las cosas, de imponer deberes y de conferir derechos, la concepción de la autoridad como servicio suministra sólo parte de su análisis. Establece una condición necesaria para ser una autoridad, pero no una suficiente.

Esta objeción es más plausible. Pero para tener éxito necesita hacer frente a una duda: las diferencias entre autoridades teóricas y prácticas pueden llevar a diferencias en lo que tiene que ser establecido para confirmar que cumplen los criterios de la concepción de la autoridad como servicio para tener autoridad legítima. ¿No serían suficientes esas diferencias para mostrar que no todo el que puede ser una buena autoridad tiene autoridad práctica?

Limitando la discusión a las autoridades políticas, sabemos que una parte importante de su rol -mejorar los servicios públicos, la seguridad personal, la seguridad contractual y de otras transacciones comerciales- les exige tener éxito en la coordinación de la conducta de un gran número de personas. Esa habilidad no es suficiente para la ejecución de tales tareas, pero es necesaria para ello. Se sigue que sólo los organismos que gozan de autoridad de facto (es decir, que una parte considerable de la población de hecho les sigue, o al menos se conforma a ellos) pueden tener autoridad legítima sobre todas esas materias. De ahí que no pueda haber una autoridad política que sea desconocida. De manera similar, no puede haber una autoridad política que no ejerza su autoridad, es decir, que no emita directivas que impongan deberes, confieran derechos, etc. Podemos contrastar esto con la autoridad teórica: nuestro experto en los métodos de cultivo del siglo XVIII puede no dar nunca ningún consejo ni expresar ninguna opinión sobre la materia. Basta con que pueda hacerlo, porque su autoridad depende de su conocimiento, no de su poder sobre la gente, no de su capaci- 
dad para hacerles modificar su conducta para conformarla a sus directivas, como ocurre con la legitimidad de las autoridades políticas.

Por último, pero muy importante, tal como son las cosas en nuestro mundo, los gobiernos del tipo de los que nos son familiares sólo pueden tener éxito en cumplir las condiciones de legitimidad (según la concepción de la autoridad como servicio) si tienen autoridad para usar, y tienen éxito en el uso de, la fuerza contra aquellos que burlan algunas de sus directivas. No hay necesidad en este momento de establecer cuáles son las condiciones generales para el uso correcto de la fuerza por parte de los gobiernos. Para nuestros fines, es suficiente decir que tal derecho tiene que existir para que un gobierno reúna las dos condiciones de legitimidad, y que tiene que ser eficazmente usado. Éste es un doble obstáculo adicional en el camino de la posesión de autoridad gubernamental legítima. Es un obstáculo normativo: justificar la posesión de un derecho moral a usar la fuerza; y es un obstáculo fáctico: ser de facto capaz de usarla eficazmente. Ninguna de tales condiciones necesita ser reunida por las autoridades teóricas. ¿No muestra la existencia de estas condiciones que la concepción de la autoridad como servicio explica no quién sería bueno si se le hubiese dado autoridad, sino quién realmente tiene autoridad? Como mínimo muestran que la concepción de la autoridad como servicio reconoce y tiene alguna explicación sobre la diferencia entre estar cualificado para tener autoridad y tener autoridad. La pregunta es si esta explicación es adecuada. Esa pregunta queda aún abierta. Pero la acusación de que simplemente confunde cualificación para ser autoridad con autoridad, fracasa.

\section{CONSENTIMIENTO}

Examinemos un candidato para este elemento perdido: el consentimiento de los súbditos. De acuerdo con la perspectiva a considerar, para que el consentimiento confiera autoridad a alguien, es necesario que se cumplan las condiciones de la concepción de la autoridad como servicio. Para tener autoridad, una persona u organismo tiene que reunir las cualificaciones necesarias para sostener autoridad. Las dos condiciones de la concepción de la autoridad como servicio establecen en qué consisten dichas cualificaciones, y por consiguiente, para que alguien cualifique como poseedor de autoridad, debe cumplirlas. Pero, en realidad, para tener autoridad sobre otro también se requiere del consentimiento de ese otro.

Sin embargo, muy comúnmente, la afirmación de que toda autoridad deriva del consentimiento es considerada por sus defensores como basada en otras consideraciones, independientes del anterior argumento. Por usar los eslóganes habituales, no puede ser - dice la gente- que una persona esté sometida a la voluntad de otra salvo por su propia elección, expresada mediante su consentimiento a estar sometida a esa autoridad.

Algunas personas consideran que esta perspectiva es una aplicación, al caso de la autoridad, de una tesis más amplia, a saber, que ninguna obligación vincula a nadie excepto por su propia voluntad. Tendré que hacer caso omiso de esta perspectiva, que nos lleva demasiado lejos para tratarlo en la presente ocasión. Me centraré en la perspectiva más limitada de que al menos todos los sujetos que son personas, que son agentes autónomos, no pueden estar sometidos a la voluntad de otro excepto por elec- 
ción. Nadie puede tener autoridad sobre nosotros, y decirnos qué hacer, sin nuestro consentimiento.

No obstante, asumimos que pueden existir deberes sin el consentimiento de la persona obligada. Tengo un deber de respetar a otros que no depende de mi consentimiento de respetarlos, y menos aún de mi consentimiento a una obligación de hacerlo. ¿Para qué es, entonces, el consentimiento un prerrequisito? Una línea de argumento sostendrá que ninguna obligación cuyo cumplimiento afecta a una persona puede ser válida sin su consentimiento. Pero esto parece muy implausible. Las obligaciones de otras personas de respetarme, de no matarme, así como su deber de proteger el medio ambiente, por ejemplo, me afectan profundamente, y sin embargo ellas las tienen independientemente de mi consentimiento. Y parece plausible pensar que yo tampoco pueda liberarlos de esas obligaciones. No puedo liberarlos de su obligación de proteger el medio ambiente porque su impacto sobre mí no es central para su justificación. Pero tampoco puedo liberar a las personas de su deber de respetarme, o de respetar mi humanidad como habría dicho KANT, aunque yo sí sea central para su justificación. Cierto es que mi consentimiento puede convertir a ciertos actos, que sin él infringirían ese deber, en inocuos. Por ejemplo, al darte mi coche como regalo, convierto al hecho de que te vayas conduciendo en él de ser un robo a ser en un uso permisible de tu propiedad. Pero el efecto de mi consentimiento presupone la existencia de un deber previo, y su alcance (¿puedo consentir ser matado o ser convertido en esclavo?) está determinado por ese deber, que existe independientemente de mi consentimiento.

Así que volvamos a la sugerencia más plausible, a saber, que nadie puede intencionalmente imponer una obligación a una persona sin el consentimiento de ésta. Esta idea se supone que está ligada al ideal de autonomía personal. ¿Qué es lo que hace de las obligaciones intencionalmente creadas por otro un caso especial que requiere el consentimiento? No puede ser el contenido de estas obligaciones, porque la demanda de consentimiento no se hace depender del contenido de las obligaciones. Depende de su fuente. Dado que sólo una cosa se conoce de la fuente, a saber, que se supone que es una autoridad, la demanda de consentimiento parece depender de la relación general que se indica: una relación de una persona sometida a la voluntad de otra.

¿No da la impresión de que hemos vuelto al principio? ¿No habíamos considerado ya ese preciso punto? ¿No se trata de la pregunta moral que fue contestada antes? Si aquélla fue una buena respuesta, y nada se ha dicho que indique lo contrario, ¿por qué hemos retornado a ella? Cabe presumir que haya un sentimiento residual de que la respuesta anterior no cubrió todos los aspectos del problema moral. ¿Qué quedó pendiente? ¿Cómo lo podemos encontrar? La vía para una respuesta fue indicada antes. Vimos que el consentimiento es una fuente de obligación sólo cuando algunas consideraciones, independientes del consentimiento, lo reivindican como tal fuente. Y esas consideraciones también determinarían qué tipo de consentimiento se requiere para legitimar a la autoridad y sobre qué materias reinará.

Extrañamente, es este test lo que no encuentro manera de satisfacer. La pregunta moral fue acerca de la legitimidad de que una persona esté sometida a la voluntad de otra. Pero ese problema no se puede resolver vía consentimiento. Supongamos que me dices: «Te impongo la obligación de que vengas mañana a mi fiesta» (y 
puedes añadir: «siempre que tú estés de acuerdo, por supuesto»), y yo contesto: «Estoy de acuerdo». Definitivamente consentí ir a tu fiesta. Puedo incluso haberlo prometido. Pero, claramente, sea lo que sea que me hayas dicho, tú no me impusiste una obligación. La obligación es completamente mi propia creación. Pudiste haberme hecho una invitación de una manera divertida, o haber expresado un fuerte deseo de que vaya, nuevamente de una manera divertida. Pero tú no me obligaste a que vaya.

Ahora supongamos que me dices: «Tendrás la obligación de hacer cualquier cosa que te diga que hagas», o: «siempre que te diga que hagas algo que a mi juicio debes hacer de cualquier modo, tú tendrás un deber de hacerlo, siempre que ahora aceptes esto». Si me dices algo así, y yo acepto, entonces, antes de aceptar, y en el momento de la aceptación, yo no estaba sometido a tu voluntad; una vez que he aceptado, estoy sometido a tu voluntad. Esto es análogo a convertirse en esclavo. Yo era libre, y perdí mi libertad. En nuestro caso, yo era independiente de tu voluntad, y ahora estoy sometido a tu voluntad. Por supuesto que no es el caso que estoy sometido a tu voluntad porque así lo quiero. Podía haberlo querido cuando consentí. Pero una vez que he consentido, lo que yo quiera se vuelve irrelevante. Estoy sometido a tu voluntad lo quiera o no. ¿No plantea esto el problema moral, más que responderlo?

Como señalé, aún persiste el sentimiento de que la solución antes dada a la pregunta moral dejó algunas de nuestras preocupaciones sin contestar. Trató el problema como el de una persona que deja que otra decida por ella en lugar de decidir por sí misma. El énfasis fue puesto en «no decidir por sí misma». Mostró que no hay ninguna objeción a ello, que lo debemos aprobar cuando nos hace conformar mejor con la razón. El argumento trazó analogías entre autoridades, agentes, artefactos mecánicos, y demás. Y es ahí donde se queda corta. No advirtió que, aunque son todos casos en los que no se decide por uno mismo, hay una diferencia entre esos casos y el de la autoridad, porque sólo la autoridad implica someter nuestra voluntad a la de otro, y eso no es meramente una cuestión de no decidir por uno mismo.

Concedamos que el problema existe, que quizás la solución ofrecida hasta el momento lo ignora. Subsiste el hecho de que el consentimiento no resuelve el problema. Sólo puede resolver el problema cuando haya una razón para que tal consentimiento nos vincule, y no hay ninguna razón así distinta de aquella que puede prescindir del consentimiento pero no puede explicar por qué un solo acto de consentimiento puede someternos de por vida a la voluntad de otro; o sea, la de que la autoridad nos hará conformarnos mejor con la razón. Se debe advertir que, al negar que el consentimiento sea necesario para la legitimidad, no estoy negando que tenga alguna importancia. Sospecho que la manera en que es tratado en el Derecho de algunos países muestra que se considera significativo, pero no para la legitimidad de una autoridad. A los ciudadanos naturalizados y a los titulares de algunos cargos del Estado a menudo se les exige que expresen su consentimiento formal, pero no necesariamente para la legitimidad de la autoridad. En tanto que el Derecho pretende autoridad sobre todos nosotros pero sólo requiere el consentimiento de algunos, no considera al consentimiento como necesario para su autoridad. Pero el requerimiento de consentimiento puede mostrar que se toma para expresar alguna actitud más específica que se considera requerida en algunos contextos en particular. Más allá del Derecho podemos sentir que el consentimiento marca una diferencia: «ahora (habiendo consentido) 
usted sólo puede culparse a usted mismo», decimos a veces. No puedo investigar aquí acerca de tales posibilidades, simplemente reiteraré que las razones dadas no establecen que el consentimiento sea una condición de la autoridad.

Quizás, sin embargo, la popularidad de las explicaciones de la autoridad basadas en el consentimiento tenga algo que decirnos. Quizás, aunque equivocadas, apunten en la dirección correcta. La cuestión es una cuestión relativa a la apropiación. El aspecto del problema moral que estamos enfrentando no es el de los límites a la propia libertad que ponen el Derecho u otras directivas autoritativas. Es el de que los límites son impuestos deliberadamente y que son impuestos por otro. No son límites puestos por mí. Las explicaciones basadas en el consentimiento son atractivas porque buscan convertir a los límites en límites propios del agente. Son quiméricas porque no logran hacerlo. Siguen siendo límites impuestos, deliberadamente impuestos por otro. Mi consentimiento histórico no puede tener la importancia puesta en él; no puede convertir a los límites en propios.

Lo que necesitamos, cabe pensar, es otra manera de explicar la apropiación, de explicar cómo las órdenes de la autoridad pueden perder el carácter de sometimiento de una persona a la voluntad de otra. Ahí es donde comienza la búsqueda de identidades colectivas.

\section{IDENTIDADES COLECTIVAS}

El defecto de las teorías del consentimiento consiste en que huyen de la realidad. Afirman que lo que no es mío es mío, a pesar del hecho patente de que me vincula independientemente de mi voluntad y a menudo en contra de mi voluntad. Lo mejor que se puede decir a favor de ellas es que nos convierten a cada uno en esclavos de nuestras propias decisiones cuando éramos jóvenes. Pero hay otra vía. Una regla o directiva puede ser ni impuesta sobre mí por otro ni hecha por mí. Podría ser hecha por "nosotros", por una colectividad de la cual formo parte. Los ejemplos más simples y menos polémicos derivan de empresas colectivas limitadas. Seis amigos podemos ir a un viaje de aventura juntos u organizar una fiesta o una conferencia juntos. Y podemos decidir, consultándonos mutuamente, qué hacer para perseguir nuestra empresa colectiva, decisiones que nos vinculan a todos y cada uno de nosotros. Así como ninguna de ellas es tomada por mí, ninguna de ellas es impuesta sobre mí por la voluntad de otro. Son decisiones tomadas por nosotros. ¿No es una condición adicional necesaria para la legitimidad de la autoridad que actúe para una colectividad, de forma tal que sus directivas no son impuestas a los miembros de ese grupo sino que son sus propias decisiones tomadas colectivamente, quizás por medio de sus agentes o representantes?

\section{1. ¿Actúan las autoridades en nombre de la gente? Colectividades y acciones colectivas}

Hay un discurso sobre las colectividades, su identidad y acción, y cómo nos relacionamos con ellas cuando decimos que "nosotros", queriendo decir la Universidad 
de Oxford, "hicimos esto o aquello" o "valoramos mucho estos ideales", etc. Éste es un discurso comprensible, y por tanto tiene condiciones de verdad, y hay estados de cosas en virtud de los cuales tales enunciados son verdaderos o falsos.

No tengo ninguna razón general para pensar que no existen autoridades prácticas, es decir, autoridades con un derecho para gobernar u ordenar, que no son los órganos de colectividades del modo en que los gobiernos son los órganos de países o Estados. Pero bien puede ser que los casos en que las autoridades actúan en nombre de colectividades y son órganos de colectividades sean los típicos. Pueden ser el paradigma en relación al cual entendemos todas las autoridades. Así que concedamos ese punto, necesario para el éxito de la idea de que la respuesta al problema moral es que las acciones de las autoridades son nuestras acciones.

Éste no es el lugar para investigar las condiciones de verdad de las proposiciones sobre la acción colectiva. Pero un aspecto de tal investigación es importante para nuestro propósito: ¿es el caso que una universidad, un país, un gobierno, o cualquier otra colectividad, es mi universidad, país o gobierno sólo si me identifico con él?

La noción de identificación es a la vez importante y oscura, pero pienso que no puede haber ninguna duda de que la respuesta a la pregunta es negativa. La Universidad de Oxford es mi universidad tanto si me identifico con ella como si no. Tu país es tu país te guste o no, tanto si te sientes ajeno a él como si no, y este gobierno es el gobierno de todas las personas de este país, por mucho que ellas lo odien. Hubo momentos en el pasado en los que muchos anglo-irlandeses no se identificaban con Irlanda y su gobierno. No lo consideraban su Estado ni su gobierno. Pero Irlanda era su Estado, y su gobierno era su gobierno. No de manera infrecuente encontramos en un país individuos o grupos que no se identifican ni pueden llegar a identificarse con su país, ni consideran a su gobierno como el suyo. Ellos no usarán el lenguaje del "nosotros", como en "nosotros acabamos de cambiar el Derecho para hacer más difícil quedarse en el país a quienes buscan asilo". Su negativa, a menudo su incapacidad para usar tales locuciones, es algo muy significativo, pero no cambia el hecho de que ése es su país, su Derecho y su gobierno.

\section{2. ¿Se resuelve el problema moral cuando la acción de la autoridad es la nuestra?}

El hecho de que las personas puedan sentirse ajenas a sus países, que puedan negarse a hablar de lo que "nosotros" hicimos al hablar de sus países, suscita severas dudas acerca de la tesis de que la respuesta al problema moral sea que las órdenes de las autoridades son nuestras órdenes, incluso cuando somos sus súbditos. Dígaseles esto a las personas que se sienten ajenas a sus países o a sus regímenes. Dígaseles que son ellos quienes aprobaron las leyes que consideran anatemas, etc. Es una triste forma de engaño pensar que el hecho de ser la autoridad de su país hace que las órdenes de esa autoridad sean sus propias órdenes en algún sentido que resuelva el problema moral.

Una respuesta a esta cuestión es decir que hay un sentido diferente de pertenencia, de que un grupo sea nuestro grupo, de que sus acciones sean nuestras acciones; un sentido que sí llena el vacío que estamos considerando. Quizás. Puede haber un 
sentido de pertenencia a un país, o de identificación con su régimen (o sea, con su constitución política), un sentido que permitiría a la gente afirmar que las acciones de la autoridad con la que se identifican son sus propias acciones, disolviendo así el problema moral. La pregunta es: ¿¿significa esto que el poder legítimo de las autoridades está limitado a las personas que así se identifican con las colectividades que las autoridades representan? ¿Significa esto, por ejemplo, que los anglo-irlandeses que no se identificaron con Irlanda y su gobierno no estuvieron sometidos a su autoridad, que no estuvieron sometidos al Derecho de Irlanda?

El problema de los límites de la autoridad del Estado tiene un alcance aún mayor. Tendemos a creer que los Estados tienen alguna jurisdicción extraterritorial y que en todo caso tienen jurisdicción territorial sobre todas las personas dentro de las fronteras del Estado. Pero no esperamos que los visitantes se identifiquen con el Estado o con su régimen. Sería bueno que la población de un país se identificara con él y con su régimen. Pero no hay ningún argumento razonable para negar que cuando el Estado tiene alguna autoridad legítima, su autoridad se extiende más allá del gobierno de aquellos que se identifican con ella.

La identificación puede jugar un papel importante en una teoría de la legitimidad de otra manera. Se podría decir que un requisito de la legitimidad del Estado, y de sus autoridades, es que sería razonable que sus ciudadanos se identificaran con él. Se piensa que la identificación no es un hecho bruto, es una actitud, que, igual que las creencias, emociones y deseos, es sensible a razones. Hay, o puede haber, razones para identificarse y razones para no identificarse. Por lo tanto, algunas veces identificarse es razonable, y otras no ${ }^{23}$. Se podría afirmar que es una condición de la legitimidad de una autoridad el que sea razonable para sus súbditos identificarse con ella. Puede que así sea, al menos en el caso de algunas autoridades. Pero no es sorprendente que crea que la concepción de la autoridad como servicio provee las condiciones para el cumplimiento de este requisito (los otros tienen que ver con las relaciones del individuo con la autoridad o el organismo en el nombre del cual actúa). De esta manera, esa idea no ofrece ni una crítica ni un complemento a la teoría de la concepción de la autoridad como servicio.

\section{3. ¿Deben las autoridades legítimas actuar también en nombre de colectividades? ¿Tiene ello importancia?}

Este breve argumento se basa en el hecho de que las personas, incluyéndome, que creemos que las autoridades políticas pueden alguna vez ser legítimas, sostenemos opiniones sobre su legitimidad en muchos casos concretos que no pueden conciliarse con la opinión de que los organismos políticos sólo tienen autoridad legítima sobre las personas que se identifican con ellos o con los regímenes a través de los cuales ellos actúan. Algunos pueden sostener que deberíamos revisar nuestras creencias sobre el alcance de la autoridad. Mi sensación es que eso sería un error. El problema de la apropiación, al cual se supone que la identificación es la respuesta, es una cuestión mal enfo-

${ }^{23}$ Algunas personas dirían que a veces uno debe o tiene un deber de identificarse, aunque yo lo dudo. 
cada. No es parte de nuestra comprensión normal de la autoridad que sus acciones sean las acciones de sus súbditos. Al contrario, la comprensión normal es que la autoridad implica una relación jerárquica, que implica una imposición sobre el súbdito. La concepción de la autoridad como servicio explica cómo y cuándo tal poder se puede justificar, al menos en el sentido de ser para bien. La búsqueda de una solución al problema de la apropiación quizás sea mejor verla como un ideal al cual aspirar: sería bueno, deseable, que la mayoría de los súbditos de una autoridad política se identifiquen con el régimen para el cual ella actúa. Pero la identificación no debe ser considerada como una condición de legitimidad.

(Trad. de Paula Gaido) 